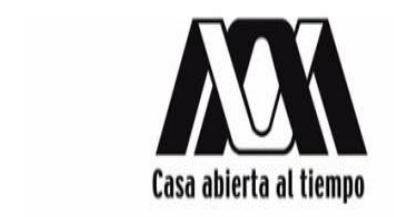

UNIVERSIDAD AUTÓNOMA METROPOLITANA

UNIDAD IZTAPALAPA

División de Ciencias Sociales y Humanidades

\title{
EL CONCEPTO DE INTENCIONALIDAD ANIMAL EN FILOSOFÍA, ETOLOGÍA Y PSICOLOGÍA COMPARADA.
}

\author{
IDÓNEA COMUNICACIÓN DE RESULTADOS PARA OBTENER EL \\ GRADO DE MAESTRÍA EN FILOSOFÍA DE LAS CIENCIAS Y DEL \\ LENGUAJE
}

TESIS QUE PRESENTA: LIC. MARÍA DE LOURDES RAMÍREZ ARgONZA.

Matrícula: 2123802257

\begin{abstract}
ASESOR: DR. JORGE MARTÍNEZ CONTRERAS
JURADO: DRA. AURA LETICIA PONCE DE LEÓN CONTRERAS

DR. JORGE ROBERTO ORNELAS BERNAL

Dra. Violeta Beatriz AréChiga Córdova
\end{abstract}

JULIO DE 2014 
ÍNDICE

Dedicatoria 2

Agradecimientos 3

Introducción $\quad 4$

Antecedentes: El Problema de la intencionalidad animal: Sus orígenes $\quad 6$

Capítulo 1: Definición abarcante de intencionalidad animal 14

Capítulo 2: Problema de las otras mentes y las posibles formas

de contrarrestarlo 16

Capítulo 3: Intencionalidad animal en sentido filosófico 23

Capítulo 4: Intencionalidad animal en sentido etológico y psicológico 40

4.1. Concepto y visión de la intencionalidad en las ciencias 42

4.2. Konrad Lorenz y la intencionalidad en animales 44

4.3. Niko Tinbergen y la estructura de la conducta 46

4.4. La evolución mental de los animales 48

Capítulo 5: Teoría Mental en animales

Conclusiones $\quad 56$

$\begin{array}{ll}\text { Bibliografía } & 59\end{array}$ 
DEDICATORIA

Para mi familia, mis tantos gatos (en especial a Mina y mi gato adorado, Micho) y mi perro Cíber, quien nos acompañó hace tiempo en esta vida. De mis mascotas nace mi inspiración en este trabajo. 


\section{AGRADECIMIENTOS}

Le agradezco extraordinariamente a mi asesor de tesis por su gran apoyo, le admiro enormemente, gracias Dr. Jorge Martínez Contreras. Desde el final de año de mi licenciatura descubrí que la filosofía no es un círculo cerrado en sí mismo, sino que es una visión que se relaciona con cada aspecto de la vida y descubrí que ocurre de igual modo lo contrario, que cada aspecto de la vida se relaciona con la filosofía. También, gracias a sus clases de corte evolucionista encontré una forma de relacionar el meta-análisis que realizamos nosotros los filósofos en la vida real: encontrar el modo en que encajamos realmente, nosotros los humanos, en la vida concreta del lugar donde vivimos, la Tierra. Desde entonces, he apartado de mí ciertos dogmas como son, la superioridad humana y, esto incluye la diferenciación de las especies o la necesidad de la religión. He también descubierto otras dimensiones naturales de fenómenos que por lo general se creen únicos del ser humano, como es el amor, el altruismo, el odio o la reflexión.

Sin duda, también agradezco a mis lectores, Aura Ponce de León, Violeta Arechiga Córdova y Jorge Ornelas Bernal, a quienes he conocido por distintas circunstancias, admiro su labor como investigadores; despiertan en mí un gran interés por la dimensión filosófica que abordan. Me permito agradecer especialmente a Jorge Ornelas, por su muy valiosa ayuda y cercanía. Has despertado en mí un amor hacia la filosofía actual y, sobretodo, hacia la epistemología, además de que admiro mucho tu ser como persona y como filósofo.

Agradezco infinitamente a mi familia quienes han sido mi mayor soporte y mi mundo: mi mamá, mi papá, mi hermana y mi tía.

Gracias a mis colegas del CEDAR por su compañerismo, por su ayuda. He aprendido bastante de sus temas de estudio.

Les agradezco mucho a mis amigas y amigo más cercanos, María Elena, Judith y Ana Laura, y a mi amigo Emmanuel, por permitirme desahogarme y estar feliz en su compañía cuando más lo he necesitado en el proceso de la creación de mi tesis de maestría. Gracias también a mis compañeros de filosofía por su interés en mi tema y por su amistad, sobretodo a Miguel a quien admiro por su constancia. 
Introducción

¿Qué entender por intencionalidad? Actualmente, este cuestionamiento es un tema de debate filosófico tocante también por otras ciencias. Para la filosofía actual es un problema de carácter epistémico, ontológico y metafísico que se relaciona con la conciencia, la mente, la representación, la comprensión, la significación, la inteligencia, las intenciones, el comportamiento y probablemente más circunstancias, pero sobretodo, el hecho es que, al tratar de responder el cuestionamiento es imposible no ponerlo en relación con los demás seres vivientes, ya que no somos únicos en el lugar que habitamos; por esta razón, si la intencionalidad es un fenómeno que se da de hecho, cabe preguntarse si también ocurre en los animales. Conforme esta justificación, los temas a desarrollar en nuestro trabajo serán primero, con respecto a si hay compatibilidad de visiones entre lo que concibe la filosofía y lo que concibe la etología y la psicología comparada por la intencionalidad animal; el segundo tema surge precisamente de esta comparación de visiones entre estas disciplinas: por qué si es posible atribuir intencionalidad en animales, o por qué no es posible atribuir intencionalidad a los mismos.

De este modo, en la presente investigación tendremos dos objetivos: a) realizar un análisis histórico-descriptivo de algunos de los principales exponentes de intencionalidad animal en los ámbitos de la filosofía, la etología y la psicología del comportamiento; esto lo explicaremos en los antecedentes y en los capítulos tercero y cuarto para ofrecer un contexto comparativo acerca de cómo se entiende la intencionalidad pensada desde estos tres campos de investigación; b) también ofreceremos una definición mínima de intencionalidad en el capítulo primero, para defender que todos los animales no humanos* sí tienen intencionalidad en sentido práctico, pero sólo algunos tienen intencionalidad mental.

En el quinto capítulo ofreceremos algunos argumentos que ofrece la teoría de lo mental en animales, pensada desde el campo de la psicología comparada,

\footnotetext{
* En lo sucesivo usaré animales para el caso de animales no humanos y humanos para el caso de animales humanos para evitar confusión.
} 
que recurre a argumentos por analogía para explicar el comportamiento animal como intencional en sentido mental. 
Antecedentes: El Problema dE la intencionalidad ANimal: Sus ORÍGENES.

En esta sección creemos pertinente ofrecer un contexto de algunos de los distintos modos en que se han caracterizado a los animales y su modo de acercarse e interpretar sus entornos y a los sujetos a su alrededor, por algunos de los filósofos de la antigüedad y modernidad.

a) Filosofía clásica, filosofía medieval y filosofía árabe.

Desde la Antigüedad surgen las posturas teóricas que se han considerado clásicas en torno a la intencionalidad animal, como la de Aristóteles (De Anima ${ }^{1}$ ). Nosotros creemos encontrar en este filósofo un pensamiento acerca del papel de la racionalidad como punto de partida para establecer el lugar de cada ser en el mundo, colocando al humano por encima de los animales gracias a la posesión de un alma racional, mientras que las acciones de los animales están determinadas por el instinto y las sensaciones (Acerca del alma, II, 2, 413b- 414b; III, 10, 433a). Asimismo, pensamos que posteriormente, ciertos filósofos latinos y árabes principalmente, como Tomás de Aquino (Suma de Teología, q. 75) o Alberto Magno (Sobre el alma) siguieron esa misma línea aristotélica que enmarca una línea divisoria entre lo que es humano y lo animal, siendo lo intelectivo propio del primero. Para Tomás de Aquino, por ejemplo, el orden natural y armonioso consiste en que el conocimiento sensible, propio de los animales y de los humanos, no conoce directamente las esencias de las cosas; sólo por medio de las facultades o potencias más elevadas, propias del ser humano, como el intelecto, es posible conocer de lo exterior a lo interior (Suma de Teología, q. 7579). No obstante, Tomás de Aquino retomó lo dicho sobre el conocimiento sensible que consideraba el filósofo estagirita, para sostener afirmativamente que

\footnotetext{
${ }^{1}$ Aristóteles. Acerca del alma, Trad. Tomás Calvo, Madrid: Gredos, 1988.
} 
éste mismo, se da también en animales, ocasionando que éstos perciban intenciones no percibidas por los sentidos externos; por ejemplo, la intención de acechar de un depredador; empero, no abrigó la idea de que tuvieran actos reflexivos ni deliberativos. Alberto Magno (Sobre el alma), quien leyó en mayor medida a Aristóteles y a Avicena (Liber de anima), consideró que los animales captan las interacciones por medio de tres sentidos internos: la estimativa, el sentido común y la imaginación; de modo que aquello que llamemos como intencional en los animales debe caracterizarse como "[aquello] hacia lo que el animal debe moverse y aquello de lo que debe huir" (Alberto Magno, Sobre el alma, III, 3, 360). Cabe señalar que ninguno de estos filósofos de la antigüedad, utilizaron el término intencionalidad en sí, más bien hablaron del fenómeno de significación que podrían tener los humanos y de esto se sirvieron para preguntarse si los animales también significan el mundo. Este ejercicio de pensar en ello llevó al menos a Alberto Magno a concluir que los animales logran percibir ciertas intenciones no tácitas exteriormente. Esto desde nuestra perspectiva tiene el mismo sentido de significación humana y es traducible en intencionalidad como la que definió Brentano (1874) y Searle (1983): direccionalidad de la mente al mundo y del mundo a la mente.

b) Filosofía de Montaigne y filosofía cartesiana.

Posteriormente, y después de lo que se discutió en la Edad Media y el Renacimiento sobre el lugar y papel primordial del ser humano en el mundo y su relación con lo divino, surgieron dos visiones de gran peso para el debate sobre la conciencia animal. Una de ellas fue la de Montaigne (Ensayos, 1580), la otra fue la de Descartes (1637). Ambos tuvieron posturas completamente contrarias. Del primero, Montaigne, se desprendió una postura escéptica en cuanto al pedestal humano como sujeto reinante en este mundo. Otorgó, contrariamente a las creencias religiosas dominantes de su tiempo, un importante lugar a los animales, 
pues tuvo la firme creencia de que compartimos las mismas capacidades: mentales, sociales, económicas, existenciales, entre otras.(Ensayos, 1580), lo que significa que de hecho encontramos en aquéllos capacidades que creemos únicas del humano, como el reír, llorar, comunicarse, tener un lenguaje interior, manifestar altruismo o venganza, capacidades para realizar operaciones matemáticas y, sin duda alguna, para actuar por voluntad (Martínez Contreras, 2002: 40). Podemos inferir que no dudó en atribuir significación consciente de los hechos en animales, ya que cree en una igualdad entre ambos seres, [en el sentido en que ellos pueden captar y significar mejor el mundo que los humanos. Al respecto se pregunta Montaigne: "Cuando yo me burlo de mi gata, ¿quién sabe si mi gata se burla más de mí más que yo de ella? Nos distraemos con monerías recíprocas; y si yo tengo mi momento de comenzar o de dejar el juego, también ella tiene los suyos" (Ensayos, XII, 389). Su postura escéptica, en especial sobre la "superioridad" de los humanos, lo llevó a trascender la diferencia entre unos y otros, proponiendo directamente la igualdad y afirmando que, en efecto, el ser humano no es más que un animal, uno que, sin embargo, es miserable y triste ya que carece de entendimiento entre sus semejantes, aún con sus facultades que se dicen más desarrolladas que ningún otro ser.

Descartes (1637), por su parte, se plantea el problema de la conciencia en animales y en humanos de manera radicalmente distinta a Montaigne. Retoma la escisión de la filosofía antigua sobre la relación mente-cuerpo y sujeto-objeto, considerando que hay una preponderancia en la res cogitans (materia pensante/materia espiritual), frente a la res extensa (lo material y corporal), ya que nuestra capacidad de pensar es el medio por el que significamos a los objetos. De este modo, el punto de vista epistemológico cartesiano en cuanto a la comparación entre los "reinos" humano y animal, reside en que la experiencia sensorial humana es de distinto talante a la de los animales, puesto que el humano tiene la intuición o capacidad de concebir su propia existencia conscientemente (autoconciencia) dada su capacidad de conocer sus propios estados mentales de modo certero e infalible (Descartes, 1641) de ahí el acceso 
privilegiado de primera persona que Descartes creyó tienen los humanos y del que carecen aquéllos. En otras palabras, nos distinguimos de los animales porque el acceso a nuestra mente es directo, mientras que ellos carecen de esta habilidad. Sin embargo, Descartes añadió a esta distinción epistémica entre humanos y animales que, en principio, no hay una distinción cuantitativa entre ellos y nosotros, pues ambos constamos de partes semejantes (cuerpo, como parte de la res extensa), que llevan a cabo operaciones físicas, que funcionan mecánicamente. No obstante, pensará el filósofo francés, sí hay un hecho que enmarca una diferencia cualitativa, en tanto que el cuerpo humano sólo es una máquina que sirve a la res cogitans humana, mientras que en los animales únicamente hay un nivel mecánico y no espiritual. Esta visión es la que lo condujo a considerar que los animales son autómatas incapaces de contener una res cogitans, pues sólo están capacitados para reaccionar de la manera determinada que dicta el instinto y no la razón. Por tanto, los animales, bajo el juicio cartesiano, carecen de autoconciencia entendida como aquella capacidad de significar el mundo y a ellos mismos.

Ahora bien, la crítica a la epistemología cartesiana permite que se evalúe tanto moralmente, como epistemológicamente la concepción mecanicista de la existencia animal, pues hoy en día, concebir a un animal no humano como una máquina puede considerarse inhumano, a causa de que, desde un punto de vista ético, por lo menos, ambas clases de seres son seres vivos, como lo demuestra la semejanza de nuestra estructura biológica: ambos seres vivos respiran, se reproducen, se alimentan y actúan de manera autónoma. La crítica epistemológica, por su parte, corre en dos sentidos: el primero se sustenta en el debate al respecto de considerar a la materia pensante como un criterio necesario y suficiente capaz de justificar la diferencia entre una máquina, un animal y un humano, ya que es posible atribuir modos de pensamiento a cualesquiera de ellos (Dennett, 1992); el segundo sentido se centra en el debate al respecto de la transparencia e infalibilidad del acceso privilegiado a la mente (ídem), pues, más bien, nuestro acceso no es completamente infalible, más bien debería pensarse 
que el que obtenemos de nuestras propias experiencias y estados mentales, se da en grados de fiabilidad frente a nuestras propias experiencias. Cada sujeto humano puede equivocarse al decir que tiene un dolor en un lugar preciso, pero también puede estar muy seguro de tenerlo. En cuanto a los animales, es difícil negar que ellos sepan que sienten una experiencia dolorosa, pues tienen nervios sensoriales que despiertan su nivel consciente y probablemente un nivel autoconsciente, ya que saben que son ellos los que experimentan sensaciones dolorosas y no otro. Cabe señalar que el problema de mayor peso para atribuir conciencia y autoconciencia en animales no humanos se centra en el acceso a su mente.

\section{c) Psicología de Brentano.}

Es necesario resaltar a Franz Brentano (1874) como aquél que originó la nueva perspectiva sobre el problema de la intencionalidad, el cual se dedicó a describir propiamente el concepto mismo de intencionalidad. A partir de su definición: direccionalidad de la mente hacia sus objetos propios (es decir mentales) (Brentano, 1874, 88), se han desarrollado distinciones diversas que la filosofía analítica distinguió entre la intensión, la intención y la intencionalidad, entre estado intencional e intencionalidad, conceptos de los que hablaremos en el tercer capítulo.

En cuanto a la tesis del mencionado filósofo, descrita en Psicología desde el punto de vista empírico (1874), se centra básicamente en tres puntos con respecto a la intencionalidad: el primero consiste en que todo estado mental hace referencia a aquello que los filósofos escolásticos consideraron como "lo intencional" (inexistencia intencional); es decir, a aquellos fenómenos que no son físicos, sino psíquicos (Brentano, 1924: 88). La característica principal de los fenómenos intencionales psíquicos es que pueden referir bidireccionalmente hacia a los objetos externos, o bien referir a los mismos objetos mentales; un deseo, por ejemplo, puede referir a algo inexistente, como a una fantasía. La segunda 
característica principal sobre la intencionalidad se centra en que los fenómenos psíquicos son representaciones (ídem); ya que son objetos que se nos aparecen, "como cuando vemos un color" (ibíd::148). Y la tercera característica principal consiste en que las representaciones pueden ser juicios, porque todo fenómeno psíquico "puede ser admitido o rechazado" (ibíd:: 82); justamente, cuando se juzga se pone en relación a la conciencia con la realidad porque el objeto se recibe en la conciencia doblemente: como algo representado y como algo afirmado o negado. Fenómeno que se suscita en lo que llama Brentano "conciencia interna" (ibíd: 155).

Ahora bien, la situación de los animales frente a esta descripción de la intencionalidad (como direccionalidad de los fenómenos mentales o psíquicos hacia sus objetos), la considera en cierto grado incierto, pues, destaca el hecho de que sólo de manera indirecta poseemos conocimiento de la vida psíquica de ellos, pero no niega que tengan vida psíquica, pues partiendo de Aristóteles, consideró que compartimos ciertos fenómenos psíquicos como la fantasía y la memoria (ibíd.: 143-145); lo que tenemos de incierto, desde su perspectiva, es saber si éstos tienen la capacidad de representar y emitir juicios afirmativos o negativos, pues carecen de lenguaje para hacerlos explícitos. No se promulgó tácitamente si tienen o no intencionalidad.

d) El conductismo psicológico.

Una escuela de corte psicológico que inaugura el estudio de la conducta animal no humana y humana, desde una perspectiva experimental y científica, es el conductismo. Hay distintas variantes del conductismo, pero, de acuerdo con los fundadores de esta corriente, como J. Watson (1913), Pavlov (1927) y Skinner (1974), debemos entender a aquélla como una escuela que propone el rompimiento con las perspectivas dualistas (teorías de lo mental y del alma), para dar pie al estudio de la interacción natural de los organismos con su ambiente, 
interacción que se manifiesta en el comportamiento (Skinner, 1974). De este modo, la conducta se considera como algo objetivo tal como los fenómenos de la física o de la química, pues es medible, no así los pensamientos que no tienen un lugar espacial. Ahora bien, el conductismo evitó hacer uso de otras disciplinas para estudiar el comportamiento, ya que consideró que lo mental y los fenómenos de aprendizaje son propiedades de la conducta; por ello, esta corriente no albergó una brecha abismal entre el hombre y el animal pues ambos son, primero que nada, seres que actúan por estímulos y respuestas (ídem). De este modo, desde el punto de vista del conductismo, hay dos clases de condicionamientos por los que nosotros los humanos y los animales nos conducimos y aprendemos: a partir del condicionamiento clásico (o pavloviano) y el operante. El clásico, pavloviano, parte del principio de que existen reflejos no condicionados: ante el alimento, un perro salivará. El psicólogo asociará entonces un ruido, una campana, que sonará con anterioridad a la aparición de la comida. El perro asociará el ruido de la campana al anuncio de la aparición de la comida: se trata de un reflejo condicionado, aprendido, pues el perro salivará no estando frente al alimento. En un segundo paso, el investigador sonará la campana sin hacerla seguir de alimento. El perro seguirá salivando, haciendo del reflejo condicionado un reflejo primario durante cierto tiempo; en efecto, si esto se repite un número alto de veces, el perro perderá ese reflejo condicionado, o secundario, pero nunca el primario que consiste, como dijimos, en salivar ante el alimento con el fin de origen evolutivo de facilitar la ingestión y digestión de los alimentos. De este modo, con el condicionamiento pavloviano ocurre un aprendizaje que consiste en asociar las respuestas a los estímulos, creando signos. Con el segundo condicionamiento, se genera el aprendizaje que provoca acciones o las inhibe según sea la consecuencia del aprendizaje, como algo deseable o no deseable. Ahora bien, una de las críticas que se le ha hecho al conductismo se centra en que el análisis de la conducta a partir de esos tipos de condicionamientos no alcanza a explicar toda la conducta, en especial no toda la humana; por tal motivo, surgieron posturas que niegan la posibilidad de conocer el punto de vista subjetivo de 
cualquier otro organismo a través del estudio de la conducta. Tal es la tesis que sostiene el problema de las otras mentes que se expondrá en el capítulo segundo. 


\section{CAPÍTULO PRIMERO}

\section{DEFINICIÓN ABARCANTE DE INTENCIONALIDAD ANIMAL.}

La definición principal de lo que es la intencionalidad a la que recurren actualmente los filósofos es la que ofreció Brentano (1874), aun cuando no utilizara dicho término. En su lugar, utilizó la inexistencia intencional para referir a la característica principal de los estados mentales (Brentano, 1874, 98). Searle, es otro filósofo actual que partió de esta concepción de Brentano para definirla más ampliamente como: "aquella propiedad de muchos estados y eventos mentales en virtud de la cual éstos se dirigen a, o son sobre o de, objetos y estados de cosas del mundo" (Searle, 1983: 17). Ahora bien, estas definiciones han sido conforme a lo que se piensa es la intencionalidad humana, pero: ¿qué entender por intencionalidad animal? En este apartado hablaremos de lo que podemos inferir es la intencionalidad animal, como intencionalidad práctica e intencionalidad mental en algunos.

Desde nuestra visión, proponemos que se entienda la intencionalidad animal conforme a dos sentidos: la práctica y la mental. La intencionalidad animal práctica, proponemos que se entienda como la agencia intencional de los animales; es decir, el actuar conforme a propósitos y fines, ya sea racionalmente o irracionalmente, reflexivamente o irreflexivamente. Por intencionalidad mental animal proponemos que se entienda como un conjunto de capacidades cognitivas conscientes que permitan comprender o significar el mundo y los individuos que nos rodean, así como el captar intenciones en las cosas y sujetos que los rodean. Capacidades como la representación o tener creencias y deseos básicamente. Cabe señalar que creemos justificarnos en atribuir intencionalidad práctica en todos los animales, de cualquier especie, pues, como Dennett señaló (1987), es posible inferir agencia intencional de cualquier cosa metafóricamente o derivadamente. En este sentido, atribuir intencionalidad a los animales sirve como 
instrumento para entender su comportamiento, así como podemos tratar de entender por qué un automóvil exhibe cierto actuar determinado cuando, por ejemplo, no enciende. Asimismo, podemos interpretar el comportamiento incluso de una estrella de mar, por más simple que parezca. No importará si les atribuimos conciencia o no, cualquier animal es capaz de actuar y comportarse al menos con movimientos que tendrán una causa, ya sea en razón de un impulso nervioso o un impulso de voluntad, como el deseo de comer.

En contraste, consideramos que la intencionalidad mental no es posible atribuirla a todos los animales, pues no todos están conformados por un sistema nervioso complejo, del cual se desprendan fenómenos conscientes, como el aprendizaje, el engaño, el recibir y emitir mensajes con cierta complejidad interpretativa, el ser capaz de comprender al otro individuo que tenga enfrente, semejante o diferente a él mismo, el formar sociedades, el ser obediente a las órdenes, el emitir emociones, e igualmente entender emociones; y quizá la lista sea aún más enriquecida y compleja que ésta que ofrecemos; sin embargo, consideramos es una lista lo suficientemente perspicaz para que represente lo que, desde nuestra postura es intencionalidad mental animal. Cabe señalar que los encargados de hacer una clasificación sistemática de qué animales tienen este tipo de intencionalidad son los científicos del comportamiento animal, como los etólogos y los psicólogos. 
CAPÍTULO SEGUNDO.

\section{PROBLEMA DE LAS OTRAS MENTES Y LAS POSIBLES FORMAS DE CONTRARRESTARLO.}

En este capítulo se expondrá la visión resultante de lo planteado por el problema de las otras mentes en relación con la posible intencionalidad que, desde nuestra perspectiva, es posible inferir en animales. Dicho problema filosófico indica que no podemos saber si hay otras mentes aparte de la mía, por lo que, aun cuando hubiera otras más, no habría acceso posible a la perspectiva de otro individuo, ya que ésta última, consiste en experiencias subjetivas experimentadas dentro de la perspectiva de la primera persona 'yo'. No obstante, consideramos que es relevante y posible deducir que otros seres vivos, como los animales, tienen mente y vida subjetiva porque podemos hacemos uso de razonamientos por analogía y por abducción (inferencia a la mejor explicación), pues así lo permite la observación de su comportamiento. Esto permitiría atribuir a los animales intencionalidad mental tal y como la definió Brentano. Por otro lado y además de hacer uso de ambos razonamientos por analogía y abducción, nosotros proponemos que es posible deducir mentalidad e intencionalidad en animales apelando al continuismo biológico y apelando a un razonamiento cartesiano apriorístico de la existencia reflexiva similar a la nuestra, puesto que, como Darwin señaló, nuestra estructura mental no es tan distinta de los animales, con lo cual ciertos animales pueden tener cierta psicología parecida a la nuestra, como tener creencias deseos. Además, sugerimos que, parafraseando el pensamiento sartreano sobre el-otro y el-para-otro, pensamos encontrar una vía y postura existencial para considerar a los animales como nuestros otros semejantes, como sujetos pensantes y capaces de representar las situaciones que le acaecen y de representarnos a nosotros los humanos, como sujetos parecidos a ellos con deseos y creencias. . 
En efecto, la aseveración cartesiana "pienso luego existo", se apoyó en una experiencia reflexiva individual que encaminó hacia la certeza del "yo soy", "existo". Ahora bien, no es claro que podamos hacer derivar de Descartes la idea de la aceptación de la existencia de otras mentes en humanos, es decir, la existencia del "otro", pues la duda escéptica sólo conduce a la afirmación de mi propia existencia y de mis propias experiencias. Ahora bien, esta perspectiva cartesiana originó el problema de las otras mentes, el cual se centra en el hecho de que los objetos se nos presentan con cierto aspecto ante nuestra experiencia y únicamente el mismo sujeto que las percibe es capaz de describir que este sabor, este color, este sonido, este tacto, etc., cualquier sensación o percepción particulares, son de su misma persona, aunque se puedan o no comunicar a los otros. $Y$ aunque se logren comunicar al otro, nunca se logrará comunicar la intensidad y cualidad personal de cada sensación, su riqueza e íntima consideración. En este sentido, el problema se centra en que, a causa de la perspectiva necesariamente subjetiva de la primera persona, resulta difícil atribuir experiencias semejantes al otro si no conocemos, ni estamos en su perspectiva.

El problema de las otras mentes, señala, en suma, la imposibilidad epistémica de formular una manera de interpretar lingüísticamente acerca de cómo conocer las experiencias de los demás; es decir, la perspectiva de la tercera persona resulta inaccesible a la perspectiva de uno mismo. Estos puntos de vista ajenos al nuestro, han sido denominados por Thomas Nagel como el carácter cualitativosubjetivo de las experiencias y percepciones (Nagel, 1974) ${ }^{2}$, que otros filósofos llaman qualia (plural de quale). Ahora bien, los filósofos se han visto en la necesidad de aclarar el estatus ontológico de este carácter subjetivo de las experiencias o estados fenoménicos. Para Kriegel (2006), éstos son estados o sucesos que acaecen para uno mismo, mas no estados que suceden en uno mismo. En este sentido, Kriegel sostiene que el criterio para afirmar la existencia ontológica de una experiencia fenoménica debe ser la capacidad consciente de

\footnotetext{
${ }^{2}$ Este carácter cualitativo de las experiencias es expresado en Nagel en su frase conocida: what is it like to be a bat en The Philosophical Review, LXXXIII, 1974.
} 
poseer alguna experiencia, pero no sólo debe suceder en uno mismo, sino que, uno mismo debe ser consciente que la tiene. Por ejemplo, si yo observo el cielo, yo misma debo estar consciente de que tengo la experiencia de estar observando el cielo para que sea una experiencia consciente (Kriegel, 2006, 199). Ahora bien, pareciera que el ser consciente de nuestra propia experiencia fenoménica liga un fenómeno resultante: la representación. Por consiguiente, parece interesante pensar en qué sentido se entrelaza la experiencia consciente con ésta última. Una de las posibles formas de pensar su conexión es la siguiente: para que una experiencia sea consciente, se necesita algún nivel de autorepresentación o imagen de uno mismo. No obstante, a partir de la postura de Nagel, hay una imposibilidad epistémica para saber si los animales no humanos exhiben intencionalidad mental como la que definió Brentano; es decir, si son capaces de representar el mundo y a sí mismos. Por tanto, pensará este filósofo, nos vemos imposibilitados para saber lo que sienten, piensan, creen o representan los animales. La conclusión a la que nos encamina pensar sobre el acceso a las otras mentes de otras especies, desde el punto de vista nageliano, consiste en que las posibilidades lógicas y epistémicas son nulas para concebir, imaginar y conocer otro punto de vista distinto al propio (Nagel 1974).

Ahora bien, esta perspectiva nageliana sobre la imposibilidad de acceder a las experiencias subjetivas de otros, evoca al siguiente argumento en relación al problema de las mentes de otras especies que Allen \& Bekoff lo exponen del siguiente modo:

a) Mental phenomena are private phenomena.

b) Private phenomena cannot be studied scientifically in nonhuman animals.

c) Thus, mental phenomena cannot be studied scientifically in nonhuman animals $^{34}$ (Allen \&Bekoff, 1997: 54).

\footnotetext{
${ }^{3}$ Los incisos son agregados corren de nuestra parte.
} 
El problema con el argumento, desde la visión de los mismos autores se centra en que el problema de las otras mentes en otras especies incurre al error como argumento, y lo sostienen mediante la siguiente réplica:

1. En razón de que las premisas de este argumento dependen de una concepción particular de lo que es fenómeno mental y, como lo mental se entiende como lo "privado", entonces debemos clarificar qué es lo privado:

En primer lugar si lo privado significa lo no percibido directamente, entonces análogamente los quarks también serían fenómenos privados, dado que no son percibidos; y, sin embargo, pensamos en su existencia, dado que son definidos haciendo uso de la abducción; es decir, se explican los quarks a partir de la selección de la hipótesis más plausible entre alternativas competidoras para la explicación de los fenómenos observables. Así entonces, los fenómenos mentales privados entendidos conforme a la definición del argumento, no es convincente ya que no ofrece otras razones por las que podamos estar en contra de la privacidad de éstos (ibíd: 53). Eso por un lado, por otro lado, las ciencias cognitivas pueden estudiar los fenómenos mentales apelando igualmente, a la definición a la mejor explicación, sobre la base de la afirmación que ofrece que la existencia de las mentes animales es una mejor explicación del comportamiento animal que otras explicaciones que puedan ofrecer otras hipótesis porque es más explicativa que, por ejemplo, negar que tienen mentes.

Ahora bien, la crítica del argumento del problema de las otras mentes en otras especies, también puede ir por la siguiente vía:

2. Podemos atacar sus premisas: La primera premisa a) del argumento es seguramente falsa si sostenemos que lo privado significa no tener efectos en absoluto, pues apelando a nuestro comportamiento humano, sabemos

\footnotetext{
${ }^{4}$ Traducción nuestra: a) Los fenómenos mentales son privados, b) Los fenómenos privados no pueden ser estudiados científicamente. c) Por tanto, los fenómenos mentales no pueden ser estudiados científicamente en animales.
} 
que nuestros estados mentales en ocasiones se manifiestan en nuestra conducta de cierto modo. La segunda premisa b) sería cierta sólo si lo privado significara efectivamente no tener efectos, pero es posible observar que la conducta de muchos animales es resultado de algo. Ese algo por analogía podemos pensar que son estados internos que modulan sus respuestas a determinados estímulos (ibíd.: 57). Por tanto, en cualquier caso, ya sea que la primera premisa sea falsa, o que la segunda lo sea, el argumento es erróneo (ibíd:: 54).

Asimismo, echando mano de razonamientos por analogía, podemos pensar que el comportamiento de los animales es semejante al de los humanos, porque podemos observar que su comportamiento los conduce a fines determinados. En este sentido, aun cuando carezcan de lenguaje natural para expresarse con claridad sus intenciones, podemos observar que por medio de ciertas señales o displays, comunican hechos. Así como un individuo humano enojado le cambia el semblante del rostro, así a un perro, por ejemplo, le cambian también los gestos si tiene el mismo sentimiento. Un perro enseñará los colmillos y ladrará, un humano abrirá la boca para emitir quejas, además de tener un semblante endurecido (Smith, 1982: 260).

Por otra parte, una segunda réplica se sostiene a partir de un punto de vista evolutivo, la cual argumentaría que hay una continuidad mental en las especies - como Darwin lo sostuvo-, porque podemos observar muchas y las mismas facultades cognitivas tanto en animales, como en humanos, de modo que la diferencia biológica no es un impedimento infranqueable. En este sentido, gracias a la observación del actuar de modo intencional en ciertos animales, podemos inferir que el comportamiento animal es efecto de algo consciente que ha conducido a los animales a sobrevivir en un medio, dadas las adaptaciones que han desarrollado gracias a las capacidades cognitivas y biológicas que podemos compartir con los animales, podemos pensar por ejemplo, en la capacidad de 
aprender de las experiencias, ambos seres somos capaces de esto. En cuanto a la intencionalidad mental, entendida como direccionalidad de la mente hacia objetos mentales sólo se podría atribuir a animales, sólo en la medida en que se pueda clasificar los rasgos psicológicos que revelen afinidades filogenéticas de las normas de respuesta entre los humanos y los animales cuando nos encontremos ante el mismo estímulo (Klopfer, 1973: 33), sólo así se podrá distinguir la continuidad mental entre ambas clases de individuos, animal y humano.

Finalmente, nos atrevemos a proponer una tercera vía que contrarresta la imposibilidad de acceso a la mente animal, la cual inferimos indirectamente del pensamiento de Sartre, que aun cuando no trató de la conciencia existencial animal y sí de la situación de los humanos, nos sirve para objetar dicha imposibilidad epistémica mencionada. A partir del rechazo de Sartre del solipsismo (1943: 150-190) se plantea de facto la existencia del para-otro como un descubrimiento empírico, que hace la conciencia en un momento determinado, pues podemos percatarnos de que existen otras conciencias como un reflejo de nosotros mismos, pues, cada individuo sólo "puede pensarse como tal [únicamente] en presencia del otro" (Martínez Contreras, 1980: 78). La mente animal puede concebirse desde un sentido sartreano como un despertar consciente del prójimo, ya sea como su semejante, o no, puede intuir que el-otro es un depredador, un otro individuo que le llame la atención por cierta curiosidad, y así reconocernos como alguna clase de sujeto, pero siempre reconociéndonos como otro a nosotros los humanos o bien a los objetos. Así, la intencionalidad sería ser-en-el-mundo que se da en la medida en que la evidencia del otro es anterior a toda experiencia concreta. Podemos inferir que los animales son capaces de reconocer al menos que hay otro, por lo que pueden situarse en cierto grado en un contexto determinado: pueden saber que están sometidos a un sujeto en un determinado lugar, que habita con otros individuos, que fuera de donde vive puede ser peligroso porque puede identificar a los-otros como peligrosos, entre quizá muchas más cosas. De modo que, aunque se objete que el conocimiento empírico del otro no proporcione la evidencia de la existencia del otro, aun así 
podemos recurrir al mismo cogito para fundar la existencia de la mente del otro, pues desde nuestra propia reflexión nos podemos percatar que somos contemplados por alguien más. En este sentido, nuestra intuición es que podemos ver en el pensamiento Sartre un acceso a las experiencias del otro, tanto en humanos, como en animales. De igual modo, implica que los animales manifiestan acceso a nuestras experiencias, pues si éstas no existieran, no podríamos explicar las relaciones de comunicación complejas que existen entre animales, en general domésticos, y humanos; actividades donde se manifiestan no sólo conocimientos, sino también afectos. Como ejemplo, podemos pensar en que un animal, un perro, por ejemplo, puede observarnos $y$, justo en ese momento, ocurre en él el fenómeno de la negación sartreana: él tiene la intuición de que soy alguien externa, de modo que mi exterioridad está separada de su interioridad, de su yo, aquello que es el "ek-stasis" de la existencia del para-otro y de la existencia delotro Sartre, 1943: 42), ya que se percata que es observado por otro y se percata que hay un otro. Su "dueña" se afirma como objeto ante una intencionalidad, la del perro. De este modo, el problema de las otras mentes puede ser solucionado apriorísticamente: no dudo de la existencia de otro ya que yo (animal humano o animal no humano) soy un objeto para el otro, y viceversa. Es algo inmediato que mi conciencia humana o animal se afirma o niega con otra conciencia humana o animal. Se dirá, por supuesto que, es necesario establecer qué animales son capaces de presentar esta reflexión inmediata de otras conciencias, labor otorgada a quien los estudie, o bien, a quien por simple deseo observe a los animales y deduzca quién de ellos es un individuo que reflexione en este sentido sartreano. 


\section{CAPÍTULO TERCERO.}

\section{INTENCIONALIDAD EN SENTIDO FILOSÓFICO}

En este capítulo tendremos como objetivo intentar exhibir lo que pensamos se entiende por intencionalidad en el campo de ciertas filosofías actuales. Notaremos, pues, cómo la intencionalidad en el campo filosófico ha sido entendida desde varios enfoques, aunque aun cuando difieren en contenido, no difieren en la forma; es decir, aun cuando los enfoques difieren en la forma de caracterizar la intencionalidad, todos ellos, coinciden en que la intencionalidad es un fenómeno mental de representación. Describiremos, pues, cinco enfoques sobre lo que podría considerarse la intencionalidad en sentido filosófico: a) el metafísico b) el fenomenológico, c) el lingüístico, d) el intrínseco y e) el derivado.

a) Enfoque metafísico sobre la intencionalidad.

Este enfoque remite a la visión cartesiana sobre la imposibilidad de representar el mundo y a sí mismo si no se cuenta con una mente separada del mundo físico. Es necesario el entendimiento como soporte del conocimiento certero, pues la percepción y la sensación no son capacidades cognitivas que generen certeza y autoconocimiento de uno mismo, salvo la certeza que sí genera certeza (Descartes, 1641); por tanto, la intencionalidad se da en términos de entendimiento y de autoconciencia. De este modo, un animal, al carecer de la res cogitans $^{5}$, es imposible que le atribuyamos intencionalidad, pues sólo los humanos poseerían esta mente inespacial e intelectiva que les permita conocer el mundo y a sí mismos de un modo certero generando un conocimiento intencional, que les permite significar el mundo y las experiencias.

\footnotetext{
${ }^{5}$ Ver supra, Capítulo primero, pp. 5-6.
} 
Por otra parte, otro enfoque metafísico de distinta índole es el ya mencionado anteriormente, el de Brentano $(1874)^{6}$, quien sugiere que cualquier enfoque sobre la intencionalidad parte de las teorías clásicas de la intencionalidad que surgieron con el término intentio en la escolástica. Ahora bien, desde la visión de este filósofo germano, la intencionalidad tiene una base representacional de los fenómenos mentales, porque éstos son fenómenos psíquicos por su presunta inespacialidad; es decir que no son fenómenos físicos medibles. La única forma en que podemos especular sobre ellos es porque los fenómenos intencionales están íntimamente relacionados con la conciencia: los actos de conciencia y los objetos de ella no se pueden estudiar por separado. De aquí otra característica de la intencionalidad desde la visión de Brentano: hay unidad de la conciencia a pesar de las distinciones cualitativas de las vivencias temporales; es decir, gracias a facultades como la memoria y gracias a la facultad consciente, sólo los humanos se reconocen como siendo los mismos temporalmente y espacialmente. En consecuencia, los animales no tienen intencionalidad ya que no se reconocen como uno mismo tras las distintas experiencias vividas por ellos espaciotemporalmente. Cabe señalar al respecto de esta negación de la unidad de las conciencias en los animales que actualmente las ciencias del comportamiento han realizado estudios con respecto a la memoria, en los que se han generado ejemplos de cómo ciertos animales logran ser conscientes de la temporalidad; por ejemplo, los colibríes miden el intervalo entre las sucesivas visitas a las flores a las que van durante el día, esto lo han corroborado experimentando con su conducta: se han repuesto flores después de diferentes intervalos de tiempo, y se ha observado que las nuevas visitas a las flores dieron seguimiento a la tasa de reposición, de intervalos de diez y veinte minutos. Esto demuestra que los colibríes aparentemente logran actualizar su memoria de cuándo y dónde la comida se encontró en cada flor y hace cuánto tiempo atrás ellos visitaron la localización de ella por última ocasión. (Crystal, 2010, 420). Este es sólo un ejemplo, pero se han realizado más experimentos en la misma relación de la

\footnotetext{
${ }^{6}$ Ver supra Antecedentes, pp. 6-7.
} 
conciencia temporal en distintos animales, abejas, perros y chimpancés, por mencionar algunos.

Finalmente, cabría decir de la teoría sobre la intencionalidad de Brentano que se derivaron dos enfoques filosóficos imperantes sobre la intencionalidad: el fenomenológico y el lingüístico. A continuación los describiremos.

b) Enfoque fenomenológico de la intencionalidad.

Nosotros partimos nuestra exposición sobre la concepción fenomenológica de la intencionalidad de los filósofos Husserl y Merleau-Ponty. De acuerdo al primero, la intencionalidad es el aspecto central de las vivencias conscientes (Husserl, 1913a), porque estas últimas, son siempre consciencias de algo. En este sentido la intencionalidad, siguiendo a Brentano, debe entenderse como aquella capacidad de ser consciente de algo. Ahora bien, es necesario saber quién es consciente en el sentido que menciona Husserl. Para éste, ser consciente de algo es observar cómo se manifiesta la conciencia y los estados conscientes en otros: la conciencia es un estado reflexivo, del cual, carecen los animales, pero algunos de éstos no carecen de estados conscientes, como la alegría, la indiferencia, el interés, el entusiasmo, etc (Husserl, 1913). De modo que no niega nuestra posible atribución de intencionalidad en ciertos animales. Es la tarea de la ciencia descubrir qué animales manifiestan estados conscientes. La conciencia, por su parte, es conocimiento puro o trascendente, que no se caracteriza por ser representación, sino que se caracteriza por ser un acto de las vivencias (Husserl, 1900-1901: 474). De este modo, niega que exista una relación interna o externa con respecto a la conciencia porque la referencia intencional no es una representación interna o externa de los objetos. La conciencia tampoco es algo sustancial que se divida en trozos porque no tiene propiedades, es más bien aquello que se mantiene cuando se pone entre paréntesis todo: es "la unidad del todo fenomenológico concreto cuyas partes [las vivencias] se conectan de un modo unitario y continuo" (ibíd., 483). Ahora bien, Husserl también se planteó qué 
actos de conciencia son vivencias; consideró que la percepción es uno de ellos. En este sentido, nosotros albergamos la idea de que los animales también son capaces de percibir y por tanto de percibir intenciones que se presentan en el exterior. Si pensamos en lo propuesto por Merleau-Ponty (1942), podríamos tomar en cuenta el anterior supuesto sugerido por nosotros: hay una comprensión de las relaciones de la naturaleza que se evidencia en el comportamiento. En este sentido, hay cierto comportamiento que se experiencia fenoménicamente, pues supone dos clases de vivencia: una experimentada por quien observa el comportamiento visto desde fuera, y otra por parte de quien vive el comportamiento desde dentro. En este sentido, los animales suponen cierta articulación interna de su comportamiento, o dicho en otro sentido, es posible afirmar, a partir de la intencionalidad descrita por Merleau-Ponty, que la ciencias del comportamiento animal pueden encontrar a variados animales que son conscientes del porqué de su comportamiento, despertando cierta clase de autoconciencia, como han concluido con ciertos estudios sobre la reflexión en diversos primates. Estudios que recaen en la observación del engaño, por ejemplo. Este tipo de comportamientos es de dos clases, funcional o intencional (Hauser, 1997: 112). El primero como un acto que acaece en virtud de que el comportamiento haya sido seleccionado para confundir las acciones de los otros, mientras que la segunda clase de engaño, se advierte como un comportamiento guiado por estados intencionales, como pueden ser las creencias y los deseos, cuyo resultado es la tergiversación de los estados de creencia de otros (ibíd.: 113)

c) Enfoque lingüístico de la intencionalidad.

Un segundo enfoque, se vislumbra en la filosofía del lenguaje y la lógica. A partir de estas dos ramas de la filosofía, surge el enfoque analítico de la intencionalidad, el cual está centrado en la relación lingüística que hay con respecto a la misma. Con esta relación, se pretendió dar una mejor respuesta a la pregunta ¿qué son 
los objetos intencionales?, que trató de describir Brentano. En este sentido, la filosofía del lenguaje tuvo como objetivo hacer a un lado el problema de los objetos intencionales inexistentes, ya que pensarlos como inexistentes es problemático, pues "si se admite que los estados mentales pueden dirigirse a objetos inexistentes, o bien no se puede explicar cómo los estados intencionales incluyen una relación con un objeto, o bien se produce la supuesta incongruencia de que los estados intencionales se relacionan con objetos que pueden no existir" (Paredes, 2007: 198). Por esta razón, se tomó a colación la filosofía de Frege y de Russell sobre el análisis referencial del lenguaje "que consider[a] indispensable el hecho de que las palabras se refieran o denoten algo en el mundo para ser significativas" (ídem), además de tomar en cuenta el análisis lógico extensional, por el cual las oraciones deben ser construidas para saber su verdad o su falsedad. Mediante este armazón lógico-lingüístico se tuvo como meta establecer una relación entre los nombres de los objetos y los objetos mismos, con lo que las palabras consistieran en el objeto referido según su sentido. De este modo, desde la perspectiva de la filosofía del lenguaje, si se realiza un análisis lógico-lingüístico se consigue que las oraciones constitutivas por verbos psicológicos, -como creer, saber, desear, etc.- distingan el sentido de las palabras utilizadas eliminando la ambigüedad de la inexistencia de los objetos mentales en cuanto están sujetas a valores de verdad o falsedad (ibíd: : 201).

Posteriormente, una de las aseveraciones de Russell (1919) dentro de este análisis lógico-lingüístico se concentró en considerar que las proposiciones que contengan verbos como creer, desear o esperar, son las que se deben considerar como "actitudes proposicionales", ya que a diferencia de otros verbos, como percibir u observar, sólo describen procesos psicológicos, o bien, otros verbos como el amar o ver, describen experiencias subjetivas. En cambio, oraciones que contengan los verbos determinados por Russell, logran demarcar la distinción entre sentido y referencia de una proposición, con lo cual es posible distinguir si dos personas tienen la misma creencia, deseo o si esperan lo mismo y, de este modo, saber qué proposición es verdadera o falsa. $Y$ la relación que tienen las 
actitudes proposicionales con la intencionalidad radica en que las proposiciones especifican el contenido del estado mental en cuestión.

Ahora bien, filósofos como Quine (1959) o Searle (1983: 41), han remarcado el hecho de que no se desprende de las actitudes proposicionales los estados intencionales, sino que sólo especifican el contenido mental del que puede tratarse. Quine, por ejemplo, con base en su teoría sobre la indeterminación de la traducción, aseguró que no es de necesidad que los hablantes tengan significados específicos en la mente cuando expresan oraciones. Esta afirmación se evidencia -desde su punto de vista- pensando en cómo al momento de traducir alguna oración de un hablante que evidencie una actitud proposicional, ésta se puede traducir de diversas maneras y esta pluralidad de alternativas, evidencia que "no hay nada determinado que la persona que expresa una creencia crea efectivamente" (Paredes, 2007: 208). Este supuesto que piensa Quine sobre las actitudes proposicionales, lo conduce a pensar un hecho radical, el cual consiste en asegurar que es una creencia falsa pensar que las personas tengan estados mentales intencionales; es decir, objeta la creencia de que se pueda evidenciar empíricamente -y con ello científicamente- que éstos exhiban intencionalidad. Al respecto pensamos que este escepticismo de Quine hacia el carácter intencional de los fenómenos mentales es válido, pues ciertamente, en el ámbito de la etología nunca se hace mención de este concepto, por lo que pensamos es factible que la intencionalidad mental sea únicamente un concepto filosófico, quizá sólo baste con describir las capacidades conscientes en los animales para pensar que son seres hasta cierto punto coherentes, por no llamarlos racionales para evitar ambigüedades.

Ahora bien, otra clase de análisis sobre la intencionalidad lingüística es el que ofrece el conductismo lingüístico, como el del filósofo J.L. Ayer (1971). Este mismo filósofo parte de la creencia de que conforme a las expresiones con verbos cognitivos como el 'creer', 'saber', 'pensar', hay una relación intencional en los enunciados que los contengan, a medida en que el que cree, sabe o piensa está 
dispuesto a usar símbolos de lo que crea, piense o sepa y esté dispuesto a emitir frases que refieran a lo que crea, piense o sepa. Sin embargo, este tipo de análisis conductista acarrea dificultades que tienen que ver con la "intensión" de una expresión; es decir, se relaciona con el significado de las expresiones. No obstante, el problema de definir la intencionalidad en términos de intensión, se centra en que hay una circularidad: "la intensión de un predicado $Q$ para un hablante $X$ es la condición general que $X$ tiene que creer que cumple un objeto $y$ para que $X$ esté dispuesto a describir el predicado Q a $y^{\prime \prime}$ (Chisholm, 1957:177). Debemos observar que la circularidad entre lo que se define (definiendum) y lo que define (definiens), puesto que la intensión se define a partir del hecho de creer, para luego definir el hecho de creer en términos de intensión (Paredes, 2007: 221). Estas divagaciones ocurren cuando se hace un meta-análisis de lo que un hablante significa cuando expresa un estado intencional.

Este meta-análisis lingüístico de la intencionalidad, genera uno de los principales obstáculos para atribuir intencionalidad mental en los animales, ya que éstos, al no hacer uso del lenguaje natural, se piensa por lo general, que no pueden manifestar sus creencias, emociones, representaciones y otra clase de pensamientos. Por esta razón, parecería más factible ser escépticos con respecto a si un animal no humano es consciente o no. No obstante, ciertos primatólogos han entrenado a chimpancés para que aprendan a hablar mediante señas, es el caso de Kanzi y de su hermana chimpancé Panbanisha quienes se comunicaron entre ellas mediante el sistema de señas aprendido, esto demostró la capacidad de comunicar y entender un léxico (Savage- Rumbaugh, 1994). Es así que, desde el punto de vista filosófico, un estudioso del comportamiento animal debe ofrecer criterios que evidencien la intencionalidad en animales. En el siguiente capítulo intentaremos describir los criterios por los que se enmarca positivamente, como fenómeno intencional, o negativamente, cuáles no deben considerarse así. 
No obstante, una vía filosófica que está en pro de la intencionalidad mental no dependiente del lenguaje hablado, es la que ofrece el filósofo de origen colombiano, José Luis Bermúdez (2003). Dicho filósofo señala que el lenguaje proposicional también tiene otras presentaciones, como el proto-proposicional (Bermúdez, 2003). Bermúdez parte de la connotación de Ryle ( sobre el "saber qué" y el "saber cómo" para suponer la existencia de un lenguaje del pensamiento, que en efecto no es un lenguaje público, sino privado, del cual debemos comprender su rol a partir de la comprensión de la conducta. De este modo, esas dos distinciones lingüísticas, descritas originariamente por Gilbert Ryle, sirven para comprender cómo opera el pensamiento en los animales (ídem): el ejemplo dado por este filósofo hace manifiesta esta distinción: los orangutanes son expertos en distinguir entre contenedores de líquido de diferentes magnitudes y saben elegir el que tiene mayor cantidad. Se pregunta si esto es un saber proposicional o es un saber práctico. La respuesta puede ser parcial; por ejemplo, Gilbert Ryle sostiene que, por un lado, hay variadas actividades que ponen de manifiesto cualidades mentales y que, no obstante, no son en sí mismas operaciones intelectuales y, por otro lado, sostiene que al momento de pensar, nuestro pensamiento no se desdobla en dos cosas, primero en teorizar y luego en actuar. En este sentido rechaza que el pensamiento sea subproducto de un saber teórico proposicional, sino más bien, cree en lo contrario: el saber práctico antecede al saber proposicional. Por otro lado, Jason Stanley (2001: 411) replica la postura de Ryle, para asegurar que de hecho el saber como habilidad es expresable en proposiciones, pues el saber cómo es una especie del conocer que (ídem). La postura de Bermúdez, sigue esta última opinión de Stanley: el éxito del orangután se da en términos de aplicación práctica que es certeramente una forma de conocimiento proposicional. En el ejemplo del orangután, su conocimiento proposicional se da como una intuitiva noción de mecánica de fluidos sobre la relación de volúmenes de líquido, la medida y el ancho. Una opinión parecida a la de Bermúdez la encontramos en Armstrong (1961), quien sostiene que las percepciones se asimilan a actitudes proposicionales, puesto que las primeras se 
pueden analizar en términos de disposiciones para adquirir creencias. Por ejemplo, podemos pensar en el experimento que realizó T.W. Dinger en un ratón ciego; éste aprendió a recorrer casi sin error un laberinto sin entrenamiento (Koheler, 1975: 93). Esto demostró que el animal tenía una imagen figurativa de la dirección correcta y que pudo hacer abstracciones figurativas de la longitud de las calles y amplitud de ángulos. En este sentido, para Bermúdez, es posible considerar a los sujetos que no poseen un lenguaje verbal como sujetos pensantes (atribución que no puede hacerse desde la perspectiva de intencionalidad de Frege y Chisholm, por ejemplo, a causa de la ausencia de la expresión hablada de sus estados psicológicos). La vía de Bermúdez es suponer la existencia de un lenguaje del pensamiento, que en efecto no es un lenguaje público, sino privado, del cual debemos comprender su rol a partir de la comprensión de la conducta; por eso considera Bermúdez que el orden de apreciación sobre el pensamiento debe ser inverso: primero están las actitudes proposicionales y después las oraciones; y, con la ayuda de las ciencias cognitivas, podremos asegurar que las actitudes proposicionales en tanto estados mentales, presumiblemente se realizan en estados del sistema nervioso central. En este sentido, las actitudes proposicionales son relaciones que el sujeto pensante puede ligar a oraciones propias de un lenguaje no público. Esta idea es equivalente a la idea de Fodor (1975), quien sostiene la similitud del lenguaje del pensamiento con las propiedades formales de sistemas lógico-computacionales en las que tienen interacciones causales de pensamientos que se dan entre las inferencias transicionales con la estructura física. Aplicando esa misma línea fodoriana, Bermúdez sugiere que podríamos considerar a ciertos animales como sujetos realizadores o generadores de pensamiento, cuya estructura es la de un lenguaje pre-lógico, que se puede observar en el nivel práctico del hacer y del decidir, como el que llevan a cabo los infantes; o bien, los primates y otros mamíferos superiores para alcanzar ciertos objetivos; además de que ciertos primates, como los chimpancés logran articular frases — palabras que se suceden: "quiero comer manzana roja" - que llegan a entenderse como oraciones, aun 
cuando no tengan una doble articulación que les permita separar palabras en fonemas, como en el lenguaje natural humano (Savage-Rumbaugh, 1994).

d) Enfoque intrínseco de la intencionalidad.

A grandes rasgos, este sentido de intencionalidad es el que los filósofos atribuyen al humano dada su capacidad de crear conceptos a partir de su razonamiento lingüístico-discursivo y a partir de su capacidad de representar el mundo y a sí mismos; pero, en sentido estricto, la intencionalidad intrínseca se concibe como la definió Brentano: la direccionalidad de la mente hacia sus objetos. De este modo, Searle sugiere que mediante nuestras distintas expresiones lingüísticas, logramos saber si un estado mental es intencional o si no lo es, aunque no niega el fenómeno de intencionalidad en animales, aun cuando carezcan de lenguaje doblemente articulado. Nuestra expresión discursiva es un instrumento auxiliar para comprender qué tipo de intencionalidad puede tener el animal y cuál no. De uno de los ejemplos de Searle se ilustra su concepción sobre la intencionalidad intrínseca para distinguirla de la derivada que adopta el filósofo Daniel Dennett ${ }^{7}$ :

A. Robert believes that Ronald Reagan is President.

$B$. Bill sees that it is snowing.

C. "Es regnet" means it's raining.

$D$. My car thermostat perceives changes in the engine temperature ${ }^{8}$ (idem).

Ante a estos ejemplos Searle indica que cada uno de ellos implican intencionalidad, pero el estado de cada adscripción es distinto cualitativamente. Es decir, en el caso $A$, se exhibe un estado mental intencional que se da como una creencia; en el caso $B$, éste implica intencionalidad en un sentido más amplio que en el caso $A$, ya que, en este caso se satisface en acto las condiciones de

\footnotetext{
${ }_{8}^{7}$ La concepción derivada está descrita en el inciso siguiente, el d).

${ }^{8}$ Traducción al español mía: A. Roberto cree que Ronald Reagan es presidente. B. Bill observa que está nevando. C. "Es regnet" significa está lloviendo. D. El termostato de mi carro percibe cambios en la temperatura del motor.
} 
satisfacción; es decir, se cumple con el hecho de que nieva. Además de que Searle considera que las experiencias visuales son eventos mentales conscientes a diferencia de las creencias, que pueden suscitarse en un sujeto en un estado de alerta no consciente; es el caso de una persona que dormido crea que llueva, pero puede ser falso que esté lloviendo. Ahora bien, la tesis del mencionado filósofo abre paso para la posible atribución de estados intencionales en animales no humanos, ya que aun cuando un animal no tenga un vocablo lingüístico con el cual expresar sus creencias, inconscientemente o conscientemente sí puede tener creencias: un perro puede creer que el gato está en el árbol aun cuando no lo esté.

Ahora bien, en cuanto a los siguientes casos, C y D, Searle cree que sucede algo distinto; la intencionalidad que les está implícita, no es una intencionalidad que se dé en sentido literal o que se dé de hecho, sino que se da en sentido derivado. Que se den de manera derivada significa que el tipo de intencionalidad que se les puede implicar no es intrínseca; a causa de que no son estados o eventos que existan en las mentes o cerebros de los agentes. El caso $C$ es sólo una descripción nominal que de hecho significa algo en el idioma alemán; mientras que el caso $D$ es sólo una manera metafórica de hablar sobre la intencionalidad de una máquina, de hecho le niega intencionalidad en sentido literal porque al ser una máquina, ésta no tiene percepciones.

Por otra parte, Searle señala que aunque sabemos poco de cómo se llevan a cabo los procesos de conciencia y de qué función exacta tiene la estructura cerebral para los fenómenos mentales intencionales conscientes, sí es posible hablar de una localización de cierta estructura cerebral que produce fenómenos intencionales, como son la corteza cerebral visual y el hipotálamo. En este sentido, los eventos mentales son sucesos que ocurren por el comportamiento de las micro-estructuras: las neuronas. Con esta aclaración, Searle se encamina para afirmar que no importa si decimos que lo mental es idéntico a un evento cerebral o si son fenómenos funcionales, lo importante está en que son eventos intrínsecos que suceden en la mente de un individuo, trátese de un animal, trátese de un 
humano, dadas ciertas características fisiológicas. De hecho, sostiene que, por ejemplo, si consideramos la conducta de un animal como el león en una determinada circunstancia en la que se mueva erráticamente sobre un pastizal, ésta es explicable a causa de que su conducta es originada por determinados estados intencionales, ¿cuáles?: el acecho de su presa. Pero no sólo esta última circunstancia es evidencia de un estado intencional, también es, señala Searle, el entramado que compone su acción de cazar a la presa: su estado de apetito que lo mueve a querer comer al otro animal salvaje y lo impulsa a seguirlo con el objetivo de atraparlo, matarlo y comerlo. Podemos observar pues, que hay un entramado de sucesos intencionales: el deseo de comer, el objetivo de acechar para nutrirse y toda una planificación para cumplir sus objetivos. Con esta ejemplificación, Searle dota a la intencionalidad animal de causalidad. En este sentido, a la intencionalidad en sentido general, aplicable tanto a los animales no humanos, como a los animales humanos, le es propio un aspecto teleológico. Es decir, los estados intencionales representan posibles estados de cosas futuras, puesto que pueden ser satisfechos si suceden con una direccionalidad de ajuste mundo hacia mente, y si el comportamiento es un intento para llevar a cabo los estados de cosas que se dan causalmente en una dirección de mente hacia mundo. En consecuencia, asegura Searle, es necesario no negar un rol causal en la producción del comportamiento.

Ahora bien, para este mismo filósofo, es necesario dar el criterio para saber si todas las acciones con miras hacia un objetivo son intencionales, y bajo qué criterios se debe considerar a un agente como uno que lleve a cabo acciones intencionales. El dilema está en saber si toda acción implica una intención y si toda intención implica una acción. La postura de Searle, al respecto, se centra en que, ciertamente, hay intenciones que anteceden a las acciones $y$, hay otras que suceden al mismo tiempo, es decir, que la intención está en la acción (Searle, 1983: 96). De esta aseveración deriva Searle otro postulado sobre su teoría de la intencionalidad: "todas las acciones intencionales tienen intenciones en la acción, 
pero no todas las acciones intencionales tienen intenciones previas" (Searle, 1983: 97). Searle clarifica su visión pensando en la acción de levantar el brazo, esta acción "supone" la intención previa de quererlo levantar; mientras que las intenciones que se dan en el momento de la acción, "presentan" la acción, como sería el hecho de levantar el brazo (Paredes, 2007: 256). Mediante esta ejemplificación concluye Searle que puede haber transitividad causal autorreferencial entre las intenciones previas y las que se dan en acto; es decir, que no se trata de dos actos intencionales, sino de uno dividido, porque la intención previa causa tanto la intención en la acción como el movimiento (Searle, 1983: 106).

Cabe decir que, además de que Searle piensa en la intencionalidad animal en relación a si los animales tienen autoconciencia. En este sentido sugiere -para el caso del conocimiento- que el conocimiento de los animales es instintivo, pero disposicional; es decir, es disparado por un estímulo sensorial, como cuando un perro, guiado por determinado sonido característico del amo, se dispone a ir de paseo. Por otra parte, en relación a la autoconciencia animal, Searle se percata de lo problemático del término autoconciencia (self-consciousness), puesto que, o bien se piensa en un sentido que es cierto que todo estado de conciencia implica autoconciencia, o bien pensamos lo contrario, que no todo estado de conciencia la implica. Searle más bien opta por el segundo sentido, puesto que "la mayoría de los estados conscientes, sentir un dolor por ejemplo, no necesariamente implica autoconciencia" (Searle, 1997: 6). La afirmación de que la autoconciencia puede tener lugar en especies animales es considerada sumamente controvertida en razón de que la autoconciencia implica tener un sentido del yo capaz de reflexionar sobre sus estados mentales o sea, ser autoconsciente de su propia existencia. Por esta razón es necesario preguntarse si a los animales no humanos les es posible transitar de la atención del objeto de la experiencia consciente a la experiencia consciente misma, con lo cual pasarían de un estado consciente a un estado autoconsciente. ¿Será esto posible en animales no verbales? Searle 
razona al respecto del siguiente modo: el yo "tiene que ser una entidad, tal que dicha entidad tenga conciencia, percepción, racionalidad, la capacidad de entrar en acción y la capacidad de organizar percepciones y razones, así como llevar a cabo acciones voluntarias bajo la presuposición de libertad. Si tienes todo esto, tienes un yo" (Searle, 2004: 297). Este mismo fenómeno que describe Searle como la autoconciencia, desde nuestra postura es equiparable al uso de la memoria de largo plazo en animales, pues así como en el humano mediante el uso de la memoria, cualquier individuo con facultades normales, puede ser capaz de recordarse a sí mismos en determinada edad más joven de la que tengan, así en algunos animales con capacidades de alta memoria, como en el caso de los elefantes, la memoria también juega un papel importante ya que les permite reconocer a sus congéneres vistos con anterioridad temporal ${ }^{9}$. Esto podría entenderse como el advertimiento de un 'yo' en ellos.

e) Enfoque derivado de la intencionalidad.

Este enfoque, sostenido por el filósofo Daniel Dennett, se centra en concebir la intencionalidad como algo derivado ${ }^{10}$, lo cual implica como primer hecho para entender lo que significa que hay un rechazo hacia cualquier enfoque sobre la intencionalidad intrínseca o mental. En este sentido, el hecho de que sea una intencionalidad derivada significa el rechazo de que haya intencionalidad implícita en los sistemas, el hecho es más bien que la intencionalidad es un hecho que sólo puede ser atribuible a un agente, de modo que la vía para lograr esta atribución es por medio de la "descripción de los comportamientos que los unifica según una coherencia que les es propia, la cual presenta aspectos objetivos, que [Dennett]

\footnotetext{
${ }^{9}$ Manrique, A. Memoria de elefante, [en línea]: documento electrónico en internet, 7/12/2007, Agencia Cyta Instituto Leloir, disponible en el siguiente enlace: http://argos.portalveterinaria.com/noticia/5757/Articulosarchivo/Memoria-deelefante.html.http://argos.portalveterinaria.com/noticia/5757/Articulos-archivo/Memoria-de-elefante.html.

${ }^{10}$ El filósofo John Searle es quien usa este término para este sentido de intencionalidad en Intentionality and Its Place in Nature, 1984. Y también lo utiliza Daniel Dennett en Intentional Stance, 1987.
} 
designa como "real patterns" (patrones o modelos reales). Cuando caracterizamos estos aspectos objetivos como fenómenos intencionales adoptamos lo que él ha llamado "la postura" o "la actitud intencional" (intentional stance), es decir, introducimos la intencionalidad en la descripción de los comportamientos" (Paredes, 2007: 280-281). Ahora bien, este sentido de intencionalidad se atribuye a objetos cualesquiera que asemejen tenerla, a causa de manifestar una intención con una finalidad hacia un objetivo; por esta razón, la intencionalidad se manifiesta a partir de las acciones que lleva a cabo un agente determinado, considerado como un sistema, el cual puede ser una persona, un animal, una corporación, una máquina o cualquier cosa. Cabe decir que parece extraño a primer momento que sea válido atribuir intencionalidad a casi todo, no obstante, hay un criterio para poder atribuirla, el cual es un criterio de racionalidad, pues es conforme a la posibilidad de atribuir creencias y deseos a los objetos posiblemente intencionados. De tal modo, las creencias y los deseos se pueden interpretar de acuerdo al entorno del sistema (organismo); es decir, las creencias y los deseos de un organismo no se conciben como estados internos de un sistema, sino que se describen como las relaciones que tiene un organismo con su entorno (Bechtel, 1988:101). En este sentido, la relación del sistema del animal humano se construye, por un lado, a partir del uso del lenguaje; de hecho, Dennett considera de éste que es la capacidad en la que los animales humanos basan su conducta para representar y diferenciar en su entorno (Dennett, 1987: 207), y por otra parte, gracias a los efectos físicos de las actividades del cerebro es que se puede explicar la conciencia, desmeritando lo misterioso de los fenómenos mentales.

Por otro lado, debemos pensar asimismo, que su teoría sobre la actitud intencional es un parteaguas para hablar de la intencionalidad animal, puesto que, como asegura Dennett, de manera intuitiva nos vemos dirigidos a creer que los animales tienen creencias. Una psicología popular se encamina en este sentido que parte del hecho de que los animales manifiestan conducta $y$, a partir de ella nos es posible interpretar su situación consciente. De este modo, si a partir de la actitud intencional nos es posible adscribir agencia intencional incluso a un tostador, 
(Dennett, 1987), del cual podemos inferir que su organización física lo predispone a actuar de cierto modo, aun cuando sólo sea mecánicamente, más aún es posible a los animales no humanos, ya que de algunos se evidencia agencia racional, la cual sólo se infiere sólo de organismos capaces de pensar. Para saber a qué animal no humano se le puede atribuir agencia racional, el requisito necesario será tener la capacidad de perseguir propósitos conscientemente. De este modo, a los animales con sistema nervioso desarrollado, pero carentes de lenguaje articulado, se les considera tener un nivel de pensamiento de segundo orden, pues son capaces de tener creencias. No obstante, la autoadscripción de conciencia, evidenciará pensamiento mayor al segundo orden, el cual por lo general es un nivel de pensamiento que se adjudica a los seres humanos. Empero las ciencias del comportamiento se dedican a observar en qué medida ciertos animales como los primates o los animales domésticos, tienen creencias que saben que las tienen. De esto se hablará en el siguiente capítulo.

Añadiremos finalmente dos pensamientos: el primero de éstos se centra en que el sentido derivado de la intencionalidad hace referencia a la acción racional de un agente que se suscita de manera causal y atributiva, como la sugerida por Dennett. Notemos pues que, con respecto a este sentido de intencionalidad, el debate gira en torno a dar los criterios de cómo juzgar a los sujetos a los que se le puede atribuir agencia racional; mientras que para el otro sentido de intencionalidad, el intrínseco, básicamente el debate gira en torno a los estándares para determinar qué sujetos llevan a cabo representaciones mentales y qué implican tales representaciones. Ahora bien, frente a este par de sentidos de intencionalidades, se hace patente el asunto de la intencionalidad animal que se centra en cuestionarse si los animales exhiben alguno de estos dos sentidos de intencionalidad y bajo qué criterios se les puede atribuir alguno de los dos sentidos o ambos. Para concluir, el segundo pensamiento se centra en que la concepción de Dennett sobre la intencionalidad es la más concordante con el método para inferir intencionalidad en animales por las ciencias que estudian el comportamiento 
animal y humano: la etología, la psicología y la antropología evolutiva, entre otras más. 
CAPÍTULO CUARTO.

\author{
INTENCIONALIDAD ANIMAL NO HUMANA EN SENTIDO ETOLÓGICO Y \\ PSICOLÓGICO.
}

En este capítulo tenemos como primera intención —valga la redundanciaencontrar una definición de intencionalidad en las ciencias del comportamiento y, con ello, averiguar si aquella definición corresponde con algún enfoque sobre intencionalidad en sentido filosófico. Como segunda intención, enmarcaremos dos campos de las ciencias del comportamiento: por un lado, el campo de la etología y, por otro, el campo de la psicología comparada. Describiremos cómo cada campo mencionado aborda de diverso modo el análisis del comportamiento, con lo que advertiremos que la etología aborda de manera funcional la conducta animal, sin un análisis comparativo al humano; mientras que el campo de la psicología comparada, es la que se adentra a relacionar la "mente humana" con la "mente animal". De modo que, nos atreveremos a decir que, desde nuestro punto de vista, aquella ciencia del comportamiento animal que hace uso del concepto de intencionalidad mental es la psicología comparada, mientras que la etología emplea del concepto de intencionalidad instrumental o derivada. Ofreceremos nuestras razones.

Creemos necesario enmarcar la distinción entre las dos ciencias del comportamiento más importantes, para relacionar el concepto de intencionalidad en la etología y la psicología del comportamiento. Cabe señalar que ambos enfoques se desprenden de la teoría de la evolución de Darwin, influenciando a los padres de la etología, Konrad Lorenz y Niko Tinbergen en el hecho de que el estudio científico del comportamiento animal debe empezar con la cuidosa observación y descripción de los patrones de comportamiento de una especie dada. Asimismo, Darwin influenció a un sinnúmero de investigadores de la psicología del comportamiento que albergan la tesis de la continuidad mental entre 
animales y humanos. Ahora bien, nosotros encontramos que las diferencias centrales entre ambas ciencias con respecto a la aproximación de la atribución de intencionalidad en animales son las siguientes:

a) La etología aborda el concepto de intencionalidad apoyada en el hecho de suponer que los animales actúan y aprenden de diverso modo, según la especie y dependiendo de las condiciones naturales en las que se encuentre, de modo que su intencionalidad se presenta para salvaguardar su existencia y la de su descendencia. De este modo, el punto de vista etológico sobre la intencionalidad animal es evolutivo, en la medida en que es posible observar que las adaptaciones filogenéticas ${ }^{11}$ determinan el comportamiento animal, lo cual incluye un aspecto funcional de la conducta, en el sentido de que las señales que manifiestan en su comportamiento (como estímulos y respuestas), sirven para comunicarse y llevar a cabo interacciones sociales. Ahora bien, mediante la observación de los animales en su medio natural, los etólogos logran investigar el papel que tienen los recursos ecológicos, para dictaminar qué conducta animal puede ser caracterizada como agencia intencional. Para caracterizarla como tal, tanto animales como humanos deben demostrar ser capaces de resolver problemas de manera inteligente; capacidad que contribuye a la adaptación biológica.

b) La psicología comparada, por otro lado, aborda la intencionalidad animal a partir de otro sentido metodológico, pues a partir de una especialización en experimentos y procesos controlados en animales no humanos en cautiverio, intenta estudiar los procesos cognitivos en ellos, con la intención de obtener un análisis comparativo frente al animal humano. En este sentido, la atribución de intencionalidad en los animales no humanos es de corte mental, pues se dedican a estudiar qué animales presentan una

\footnotetext{
${ }^{11}$ Las adaptaciones filogenéticas son las adaptaciones biológicas de tipo fisiológica o morfológica del comportamiento que se han suscitado por la evolución de una especie ante un medio. Piaget, J. (1977) Los procesos de adaptación, en Buenos Aires: Ediciones Nueva Visión.
} 
mente capaz de manifestar procesos de pensamiento, creencias, racionalidad, procesamiento de información o conciencia (Bekoff, 1995).

4.1. Concepto y visión de la intencionalidad en las ciencias del comportamiento animal.

Desde los comienzos de la etología en los años 1900s no se mencionó nada acerca de la noción de intencionalidad; en ese entonces esta ciencia era únicamente relacionada a los hábitos y al modo de vida de los animales (Reznikova, 2007). De hecho, ningún etólogo clásico como Lorenz o Tibergen hace uso de dicho concepto y justamente lo que intentamos hacer nosotros en este trabajo de investigación es encontrar el modo en que la visión etológica implica la atribución de intencionalidad en animales; mientras que destacaremos cómo la psicología del comportamiento atribuye intencionalidad mental en ciertos animales a partir de la teoría de lo mental.

No obstante, nosotros encontramos una concepción reciente acerca de lo que las ciencias del comportamiento de manera general deben entender por intencionalidad. La perspectiva de Hendrichs es la siguiente:

The term 'intentionality' is used for a compound organizing and steering the actions of animals, a composite complex of interrelated components of different origin and function, with different structures, states, and processes involved in the integration necessary for adequate and efficient action.

States and processes of affective and emotional arousal can be opposed and related to those of cognition and the transformation of information. All these can be opposed and related to states and processes of intentionality ${ }^{12}$ (Hendrichs, 1999:145).

\footnotetext{
${ }^{12}$ Traducción mía: El término intencionalidad se utiliza como un compuesto organizador y dirigente de las acciones de los animales, un complejo compuesto de componentes relacionados entre sí de diferente origen y función, con diferentes estructuras, estados y procesos que intervienen en la integración necesaria para la acción adecuada y eficiente. Los estados y procesos de activación afectiva y emocional pueden ser opuestos y relacionados a aquellos de la cognición y transformación de la información. Todos estos pueden ser opuestos y relacionados con los estados y procesos de intencionalidad.
} 
Con esta definición, Hendrichs señala que la concepción de intencionalidad en la ciencia biológica es concerniente a aquellos animales de los cuales se puedan detectar grados de cognición, diferencias de sentimientos y capacidad para transferir información. Ahora bien, Hendrichs establece que el criterio para atribuir este tipo de intencionalidad en animales, es a partir de establecer los diferentes niveles filogenéticos de organización mental que puedan tener los seres vivos: En un primer nivel, están los seres sin percatación (awarness) y que sólo exhiben fenómenos como conducirse o moverse; pensemos en el caso de bacterias. En un segundo nivel, están los seres que viven con percatación de su ambiente o una forma primaria de conciencia; podemos pensar en una estrella de mar, quien percibe su medio y se mueve con autosuficiencia (self-reliance). En un tercer nivel, estos diversos componentes se interconectan en animales como los mamíferos, los cuales pueden pasar de un estado simple de movimiento sin percatación de su ambiente, a un segundo nivel en el que se percaten de su medio porque lo perciben y actúan con autosuficiencia. En un último cuarto nivel, además de que hay esta misma interconexión del tercer nivel, se añaden otros tres componentes: la conciencia, el reconocimiento de uno mismo y atención a los detalles (conscientiousness); elementos presentes básicamente en los humanos, señala Hendrichs (ibíd:: 150). En este sentido, lo peculiar del tercer nivel de intencionalidad es que el estado de percatación necesita del estado de conciencia para darse este nivel, mientras que en los otros estados no necesitan que tengan una percatación autoconsciente. De este modo, desde la postura de Hendrichs, el nivel de intencionalidad mental únicamente se da en el cuarto nivel, pues la atención a los detalles (conscientiousness) es el constitutivo principal de un organismo capaz de tomar responsabilidades de sus acciones, como una forma de orientación moral. No obstante, si pensamos en el intento de Darwin por naturalizar las emociones, es posible pensar que algunos animales evidencian esa toma de responsabilidad de sus acciones de la que habla Hendrichs. Se ha hablado del altruismo en animales cuando, por ejemplo, un perro salva a su dueño; o podemos pensar en cómo diversos integrantes de una manada de 
elefantes ayudan a otras crías de diferentes progenitores de la manada, esto evidencia una clase de responsabilidad moral en sus acciones. Igualmente, la cólera en animales parece un evento que surge en chimpancés por ejemplo, tras saber que alguien más invade su territorio. El macho líder puede estar consciente de que necesita actuar con cólera para defender su territorio. Es decir, es debatible la postura de Hendrichs en cuanto a la intencionalidad humana, como siendo ésta la única que es un actuar bajo responsabilidad moral. En este sentido, nosotros sostenemos que la intencionalidad mental es también aplicable a ciertos animales en la medida en que exhiban ese despertar consciente de sus actos.

En este sentido, creemos que la labor de la etología es descubrir en las distintas especies viviendo en su hábitat natural, los distintos comportamientos que impliquen un despertar consiente en un medio social; mientras que con la psicología comparada, creemos que su labor es encontrar igualmente los comportamientos que impliquen un despertar intencional consiente a través del aprendizaje (o sin él) en un medio experimental.

\subsection{Konrad Lorenz y la intencionalidad en animales.}

Las ciencias modernas del comportamiento surgen de lo que se llevó a cabo por la etología en los años 1930's, principalmente con lo desarrollado por Konrad Lorenz (1903-1989), quien estudió el comportamiento animal mediante el uso de las observaciones comparativas, con las que concluyó que hay patrones de comportamientos establecidos en los animales y advirtió que éstos pueden deformarse por un estímulo disparado en falso (Burkhardt, Jr., 2010: 299); por ejemplo, una paloma hembra puede actuar como macho en la ausencia de palomas machos. Por otro lado, consideró importante el estudio del instinto y de la estructura de la conducta para tener una visión de la descendencia filogenética y para ver su influencia en la vida social de los animales. En este sentido, argumentó que a pesar de que los instintos y el aprendizaje sean distintos uno 
frente al otro, es posible que ambos puedan intercalarse en el comportamiento animal. Esto lo observó Lorenz en sus estudios que llevó a cabo en ciertas aves, de modo que concluyó que los considerados "animales inferiores", como las aves, se adaptan a su medio en el que viven no en gran medida por el aprendizaje, sino, mayormente por los patrones motores instintivos. Por ejemplo, la conducta de las aves grajillas en comunidad que actúa en su medio social frente a otros compañeros, de acuerdo a los impulsos sociales que surgen por los "liberadores" (auslöser) causantes de la activación de la conducta innata (Lorenz, 1986: 109).

No obstante, Lorenz consideró que los animales también ejercitan el logos; de hecho, influenciado por la filosofía de Kant, sostuvo que así como hay formas a priori de sensibilidad y entendimiento en los humanos, en los animales, hay formas a posteriori de sensibilidad y entendimiento que se dan en la filogenia de los animales, de modo que sostuvo que aquello que aprenden independientemente de lo que su sistema nervioso innato ha sido programado, es a capturar su espacio y el tiempo de manera distinta a la de los humanos, pero de una mejor manera que estos últimos, porque el modo de capturarlos que tiene cada animal, les ha permitido una mejor sobrevivencia a lo lago de la evolución en razón a su mejor condición de adaptación a su medio (Lorenz, 1961). Su intencionalidad se ve reflejada en el fenómeno de adecuación (fitness) a su ambiente, siendo un mecanismo de instrucción que se programa filogenéticamente; es decir, aparece a través de la evolución de las especies (ídem). Lorenz sostuvo con esta perspectiva neokantiana que no hay contradicción entre lo innato y lo aprendido y que el fenómeno cognitivo del aprendizaje involucra el fenómeno de representación y significación del mundo. Es en este sentido que la intencionalidad puede desprenderse del aprendizaje que manifiesten ciertas especies ya que implica formar representaciones de su medio natural (individuos y objetos).

Asimismo, Lorenz consideró que la conducta de ciertos animales no siempre es mecánica, puede ser flexible por la influencia de los procesos de aprendizaje asociativo. Por ejemplo, un pájaro puede intuir instintivamente que no debe comer mariposas nocturnas, puesto que son tóxicas para él, ya que saben que los puntos 
que asemejan a ojos en las alas de éstas representan peligro; ahora bien, ellas han aprendido a asociar estas marcas para evitar la ingestión de aquello que también las tengan. Este fenómeno, desde su visión, no es sólo un reconocimiento químico innato, sino que tiene la capacidad de asociar el peligro a partir de este reconocimiento. Lorenz comprobó este hecho disfrazando una lombriz: colocó dos figuras distintas a lado del cuerpo del gusano y observó que una codorniz sí se la comió, en cambio, cuando dibujó dos círculos a su lado, el ave no se comió la lombriz.

4.3. Niko Tinbergen y la conducta animal.

Niko Tinbergen (1907-1988) es también uno de los que instauran el auge de las ciencias del comportamiento (etología y psicología del comportamiento) al considerar a la conducta como un factor principal para comprender el modo en que representan los animales su entorno. Dicho etólogo se interesó en saber qué es lo que mueve a los animales y porqué de su comportamiento; o lo que es lo mismo preguntarse en filosofía: si se puede concebir a éstos como agentes racionales. Tinbergen consideró que las respuestas se encuentran en las causas de su comportamiento. Junto con Lorenz y su alumno Gerard Baerends, Tinbergen examinó los estímulos-respuesta en diversos animales, de lo que concluyó que los instintos son estados internos o estados de ánimo que están jerárquicamente organizados. De este modo, de un animal como, por ejemplo, un puerco espin, puede intuir que está en el estado de ánimo (mood) reproductivo, porque los cambios hormonales internos lo ponen en el estado correcto para saber lo que tienen que hacer; es decir, las hormonas disparan el mecanismo que les permite saber que están en el ánimo de buscar pareja. Tinbergen logró destacar el papel del estudio comparativo de los estímulos y respuestas como conductores de estado de ánimo en torno a la función del comportamiento. Ahora bien, en "On aims and methods of ethology" (1963), formuló las cuatro preguntas de la etología, 
que le sirvieron para introducirse en el estudio sobre lo mental en los animales. En éste sugirió que el comportamiento se analiza al menos a través de cuatro niveles: 1. A través de la causación inmediata.

2. A través del desarrollo u ontogenia de un individuo animal.

3. A través de la función de la conducta de éstos.

4. A través de la evolución o filogenia de la conducta animal.

En otras palabras, el comportamiento se puede tratar de explicar desde al menos cuatro diferentes niveles que interactúan entre sí y que aunque se pueden analizar por separado, siempre son determinantes de la conducta. Si bien antes de 1963 (del artículo de Tinbergen) se trataba sólo de explicar el nivel de la "función" o "adaptación" de la conducta (lo observable), ahora se trata de identificar cómo se integra el comportamiento al menos en los otros tres niveles. La psicología comparativa, por ejemplo, busca entender cómo especies de animales relacionadas filogenéticamente (evolutivamente: nivel 4) comparten (por el hecho de estar relacionadas filogenéticamente) formas similares de estructuras y procesos cognitivos (nivel 1) que se desarrollan a través de la vida del organismo (el sistema nervioso cambia o se desarrolla: nivel 2) y cómo esto se ve reflejado en su capacidad para adaptarse al medio (nivel 3: función adaptativa). Por tanto, a grandes rasgos, la psicología comparativa buscó unir el nivel 1 (control nervioso y cognitivo, mental) con el 3: cómo la estructura de los procesos mentales son "herramientas" adaptativas (i.e., aumentan el éxito reproductivo y la supervivencia de los individuos). Y, en este sentido, dicha ciencia ha desarrollado experimentos que sugieran una capacidad para observar el pensamiento intencional en determinados animales dependiendo de lo que arroje el intercalamiento de dichos niveles, porque mediante este intercalar, se ha obtenido una forma "útil" que ayuda a explicar lo que pasa tanto en la conducta evidente (nivel 3: función) como en los procesos nerviosos que dan origen a la conducta (nivel 1: control inmediato). 
Ahora bien, dada esta formulación que sirvió para entender la conducta y el contenido mental de los animales, Tinbergen abordó la consideración sobre los posibles actos de voluntad al cuestionarse si es que hay diferencia entre una máquina y un animal. En efecto pensó tal diferencia, pues consideró que en los seres vivos hay controles internos y externos que participan de la "retroacción negativa", como es la alimentación y la reproducción. De este modo, asentó la diferencia: lo que distingue a un animal de una máquina son tres factores: 1) la voluntad, 2) No necesitan que se conecten o desconecten por agentes externos, pues tienen un motor que enciende o apaga mecanismos internos y, 3) sobretodo, los animales siguen lo que Darwin denominaría como el principio de supervivencia y el deseo de reproducirse.

4.4 La evolución mental en los animales, visto desde el argumento de la continuidad.

A partir del siglo $\mathrm{XIX}$, distintos naturalistas plantearon razones evolutivas de porqué los animales presentan estados mentales. Etólogos como, Charles Darwin (1873), George John Romanes (1884) y Herbert Spencer (1896) postularon dicha evolución a partir de un argumento sobre la continuidad mental. En el caso del último etólogo mencionado, Spencer; éste sostiene una teoría evolutiva que puede considerarse como predarwiniana, en la que afirma que toda masa homogénea activada por una fuerza no se altera completamente, pero sí se vuelve heterogénea, con un mayor grado cada vez. En el Origen de las especies (1859), Spencer expresa la idea de la continuidad entre las diversas formas de vida psíquica, sugirió que este continuismo surge de lo más bajo (los reflejos) a lo más alto (la volición). No obstante esa gradación no enmarca un hiato entre el instinto y la razón; por lo que definió: "toda acción instintiva es un ajuste de relaciones internas a relaciones externas, y toda acción racional es un ajuste de relaciones internas a relaciones externas" (Spencer, 1896: 453-456). Ahora bien, es difícil - 
sugiere el etólogo - asentar con precisión dónde comienza el instinto y dónde comienza la razón. Esta misma distinción la extrapola también entre los fenómenos psíquicos con los físicos, postulando una especie de panpsiquismo, pues consideró que la evolución de las funciones psíquicas se localiza en el espacio, concentrándose dentro del cerebro en los mamíferos superiores (ídem). Darwin, por otro lado, además de asentar los fundamentos de la etología, establece la importancia de la selección natural. En este sentido, la filogenia queda cimentada en el comportamiento y en la selección. Ahora bien, nosotros nos atrevemos a interpretar el principio de la selección como un símil de la intencionalidad, pues las creencias, los deseos y las representaciones que ciertos animales pueden experimentar son reflejados en las exhibiciones y en los estímulos llamados signos, pues gracias a ellos se dan a entender con sus semejantes y viceversa, entienden a sus semejantes o no semejantes, queriendo significar algo, como el estado de ánimo de estar dispuesto para el apareamiento o el no apareamiento. Ahora bien, por costumbre y por asociación hay una tendencia a efectuar los mismos movimientos, pero habrá que hacer notar que, siguiendo las líneas del naturalista, hay un deseo presente en el hábito de querer gratificar determinadas sensaciones $y$, de hecho, recalca que algunas acciones asociadas cotidianamente por la costumbre en animales, pueden ser reprimidas por su voluntad, y justo en esas circunstancias, surge la libre expresividad manifestada en movimientos (Darwin, 1873, p. 28). Esto es: aquel o aquellos animales que no demuestren ser únicamente un cúmulo de respuestas innatas o instintivas, tienen volición; es decir, presentan estados intencionales que involucra estados afectivos que pueden explicarse como formas de deseos dadas ciertas creencias (Searle, 1986), podemos pensar en la alegría de un cánido ante el sonido de una puerta que se abre. Es obvio nuestra difícil interpretación ante lo que significa la alegría de éste manifestada en el movimiento de su cola, sin embargo, sí evidencia lo que nombra Merleau-Ponty: una intencionalidad corporal o como lo nombra Darwin, una libre expresividad. 
Por otra parte, de Darwin se desprende el argumento más nombrado sobre la continuidad mental en los animales y humanos. Éste es contrario a la concepción de la "cadena del ser", la cual supone que la vida del humano es ascendente como ocurre en una escalera, en la que a partir de un ordenamiento unitario, las especies evolucionan de un menor grado de complejidad a un mayor grado de complejidad. Sin embargo, Darwin se opuso a esta visión gradualista que surgió desde tiempos de Aristóteles, pensando un nuevo punto de vista: existe una continuidad y correlación entre especies; de modo que no hay una especie en un pedestal; no hay una diferencia fundamental entre "el hombre" y los demás mamíferos en cuanto a sus facultades mentales y emocionales (Darwin, 1871). De este modo, Darwin dio origen a la postura psicológica comparada en relación al comportamiento animal.

Por otro lado, el alumno de Darwin, George John Romanes, colocó al igual que Darwin, el estudio del comportamiento animal sobre una base evolutiva y comparativa (Klopfer, 1976: 30). No obstante, un aporte notable de su parte fue el análisis sobre la conciencia. Primero, desde una perspectiva general, se enfocó en saber en qué condiciones se manifiesta la conciencia, en qué momento se manifiesta como presente y en cómo podemos demostrar que un sujeto tiene conciencia (ídem). Descartó el solipsismo el cual radica en que nunca es posible saber lo acaecido en otras mentes, argumentando que, por medio del conocimiento eyectivo es posible reconocer la conciencia, pues éste es la capacidad de inferir los estados mentales de otro individuo, pues "tal inferencia es posible debido a la similitud de las normas de respuesta entre nosotros y los demás cuando todos nos encontramos ante el mismo estímulo" (ibíd.: 32). Esta concepción de Romanes, desde nuestra opinión, consideramos es una excelente perspectiva teórica adscrita en el ámbito de la etología, para lograr demostrar teóricamente que hay intencionalidad en animales, pues, éstos son conscientes de las respuestas de otros animales, ya que mediante su conducta logran demostrar que infieren que otro sujeto animal a parte de él puede tener el mismo estado de conciencia, como cuando un gato que ve a otro gato erizado, puede interpretar 
que algo sucede o que algo peligroso se le presenta y, por lo mismo, ambos se aterrorizan y se erizan. En el caso de un humano, alguien puede inferir que su vecino está preocupado, en la medida en que veo que tiene la misma respuesta de preocupación que la mía tras ver un accidente. Ambos ejemplos evidencian el fenómeno de representación tanto en los animales como en los humanos mediante la empatía, que no es más que el ponerse en el lugar del otro.

También nos gustaría comentar que vemos en la teoría de Romanes una teoría filosófica en simbiosis con una teoría biológica que, dado su sistematicidad, esboza el criterio necesario para poder atribuir intencionalidad en ciertos animales; éste es: "...El elemento distintivo de la mente es la conciencia, la prueba para la conciencia, es la presencia de la opción, y la evidencia de la opción es la antecedente incertidumbre de la acción de ajuste entre dos o más alternativas" (Romanes, 1884: 18). Dada esta concepción de dicho etólogo evolucionista, inferimos que se hace patente una noción que introduce el libre obrar en la mente animal -a pesar de que éstos estén fuertemente sujetos a los estímulos-, porque en ocasiones "logran discriminar entre los estímulos y logran hacer respuestas adaptativas que muestran alguna evidencia de elección..." (Klopfer, 1976: 32). Y, finalmente, Romanes logra poner de relieve el continuo que, desde el punto de vista evolutivo hay entre los fenómenos de cognición de los humanos y los animales con la siguiente sentencia: "La mente misma, [...] está organizada jerárquicamente en varias facultades, que incluyen los reflejos, instintos, emociones, razonamiento, y juicios y la volición y representan diferentes puntos a lo largo de un continuo, habiendo surgido cada una de su predecesora" (ibíd.: 33). 


\section{CAPÍTULO 5}

\section{TEORÍA Mental EN ANimales}

En este capítulo abordaremos la concepción llamada teoría de lo mental, la cual pensamos ha ofrecido una base para encontrar una posible semejanza en el modo en que se presenta la intencionalidad en los humanos y en los animales; es decir, aquella posible semejanza de cómo ciertos animales, como los chimpancés, tienen acceso a su propio conocimiento y pensamiento, del cual parten para interpretar a otros sujetos como agentes conscientes que persiguen algún fin.

a) Teoría de lo mental en animales (TOM).

Esta teoría se desprende a partir de la idea abordada por la filosofía de la mente contemporánea sobre la teoría de lo mental en los individuos humanos (Davidson 1984 y Dennett 1987). En este sentido, el objetivo de las ciencias que estudian el comportamiento animal en relación a la teoría de lo mental en humanos, es sostener que al menos ciertos animales tienen la habilidad cognitiva para entender a otros individuos como agentes intencionales; es decir, deben interpretar a otros individuos, tanto de su especie, como de otras distintas, como agentes racionales que obran por un propósito. Este objetivo pudiera parecer imposible dada la inaccesibilidad a la perspectiva mental de otras especies distinta a la nuestra y por la imposibilidad de estos últimos seres de comunicarse verbalmente. Sin embargo, se ha expuesto cierta evidencia empírica que demuestra la capacidad de ciertos animales con habilidades cognitivas desarrolladas ${ }^{13}$ que manifiestan TOM, podemos pensar en los primates como ejemplares. En el ensayo de Premack y Woodruff: "Does the chimpanzee have a theory of mind?", ambos autores argumentaron la evidencia experimental que brinda evidencia de la detección de

\footnotetext{
${ }^{13}$ Habilidades cognitivas como la memoria y capacidades abstractas de pensamiento como el sumar y la asociación.
} 
intenciones de la contraparte de la chimpancé Sarah: la especie humana. En este sentido, ambos autores tuvieron como objetivo demostrar la posibilidad de que la chimpancé demostrara poseer una teoría de lo mental sin gran distinción a la nuestra; es decir, intentaron demostrar que su primate tuviera la habilidad tanto de interpretar el comportamiento visto en el humano por asociación, como la capacidad de adscribirle al humano estados mentales como intenciones, conocimiento y creencias. Su justificación consistió en afirmar que dicho primate logró atribuir estados mentales en los humanos, sobre la base de las siguientes aproximaciones:

1. Sarah demostró un grado de comprensión de cómo el humano, al cual observó en un videotape, resolvía un problema con respecto a un objeto inaccesible, como el hecho conseguir una banana fuera de su alcance. Su comprensión se basó, por un lado, en ver en cuatro ocasiones distintos videos que trataron de la manera en que el humano conseguía la banana y, por otro lado, en ver distintas fotografías que demostraran la solución al problema por parte de dicho humano.

2. Tuvo un entrenamiento previo que, aun cuando no se relacionaba a dicha prueba, le permitió tener un mejor acercamiento para comprender la prueba realizada por ambos autores. Se le entrenó haciendo pruebas para inferir y relacionar, como el reunir objetos físicamente similares, se le enseñó un cierto lenguaje y le mostraron programas televisivos.

3. El primate logra comprender las actitudes del humano, ya que le son familiares dichos problemas y mediante la asociación de lo que observa con lo que la chimpancé ya sabe o ha vivido, logra comprender las actitudes del humano observado.

4. A través de la empatía, la chimpancé consigue comprender el objetivo del humano. En este sentido, Sarah logra ponerse en el lugar del otro y logra dar sentido a lo que ve. La empatía del chimpancé es una predicción de lo que la misma chimpancé haría en el lugar del humano. Por supuesto le queda restringido el saber cómo en realidad actuaría el humano porque no 
lo conoce y porque no tiene acceso a lo que piensa, pero eso no impide que interprete, desde su perspectiva la finalidad del humano.

En suma, ambos autores, están a favor de la posesión de TOM en animales, pues consideran que poseer y lograr esta capacidad cognitiva no sólo es posible a través del uso del lenguaje hablado; sino que, otra vía para su posesión es mediante el asociacionismo; podemos pensar, por ejemplo, en el caso de los infantes pre-lingüísticos, éstos forman expectativas por mecanismos de asociación (Premack \& Woodruff: 520). De modo similar, los primates con capacidades cognitivas desarrolladas ${ }^{14}$ lo hacen por medio del asociacionismo, así lo demostró la chimpancé, Sarah: al observar las actitudes de otro individuo (el humano) mostradas en diversos vídeos, ésta relacionó las actitudes que le fueron familiares -como el alcanzar una banana-, además de que logró descifrar las intenciones del humano y cómo podría solucionar el asunto que pretendía alcanzar el humano.

Ahora bien, ambos autores no dejan de lado una posible crítica que tiene que ver con la referencia de la palabra "problema", pues, cabe preguntarse si el dominio de la habilidad de resolver problemas, es o no el mismo, ontológicamente y metafísicamente hablando para ambas especies. Metafísicamente hablando, es posible pensar que el humano refiere a múltiples hechos y fenómenos cuando piensa en "resolver un problema", dada su capacidad lingüística, mientras que un animal refiere sólo a hechos restringidos, dada su ausencia de comunicación lingüística. Se pensaría que un animal sólo se restringe a solucionar problemas simples relacionados a la sobrevivencia de su especie, como el conseguir su alimento o escapar de un depredador. De este razonamiento se desprende la crítica que arremete contra la posesión de TOM en la chimpancé Sarah, ya que ésta sólo resuelve problemas familiares a su especie, como el conseguir la banana que no está fácilmente al alcance del humano, y no resuelve problemas metafísicos, como el resolver cuáles son los colores que se ven en el arcoíris; por

\footnotetext{
${ }^{14}$ Por capacidades cognitivas desarrolladas entendemos aquella sagacidad en resolver problemas complejos por medio de un uso de razonamiento inferencial.
} 
lo que, es fácil pensar que la chimpancé Sarah no razona en problemas complejos como lo haría un humano. No obstante, ambos autores piensan en respuesta a esta crítica que aún en el caso de que no se pudiera hablar de una misma extensión metafísica para el hecho de resolver problemas por parte de Sarah, no hay una diferencia abismal entre un dominio y otro sobre la capacidad de resolver problemas, ya que lo que arrojaron los experimentos realizados con la chimpancé Sarah, demostraron que aún con la falta de familiaridad de ésta con los problemas expuestos, como el tratar de conectar un cable en un enchufe, ella logró descifrar tanto la intención del humano (el conectar el cable), como logró descifrar la solución a dicho problema. En este sentido, aun cuando el domino metafísico de lo que podría ser pensar en resolver un problema sea imposible para un chimpancé, un chimpancé es capaz de poseer TOM por el simple hecho de ser capaz de un aprendizaje observacional, porque crea en su mente una teoría que parte de cuestionamientos que cualquier sujeto humano puede plantearse al ver al actor humano observado, como el preguntarse "what would the human actor do if in this sitution? What should he do? What would I like to see him do?" (ídem). Sarah, dada la evidencia que muestran las pruebas (tests), parece ser capaz de crear cuestionamientos que se distinguen por los matices verbales y que cambian toda la intensionalidad ${ }^{15}$ de las oraciones, se pregunta por las intenciones presentes, pasadas y futuras del humano, por lo que demostró una capacidad intencional, la cual es la capacidad de decisión. Sobre este supuesto, sería poco justo el negar en la chimpancé Sarah la posesión de TOM y, por tanto, la posesión de intencionalidad mental de la que estipuló Brentano.

\footnotetext{
${ }^{15}$ Intensionalidad con 's', para hacer referencia a que las tres preguntas son distintas y tienen objetivos distintos.
} 


\section{CONCLUSIONES}

- Una conclusión muy general la esbozamos del siguiente modo: Conforme a los enfoques filosóficos sobre la intencionalidad derivada, de Dennett, conforme a los cuatro niveles para el estudio del comportamiento de Tinbergen y por medio de la tesis del continuo evolucionista de Darwin y de Romanes, es posible pensar en que no es un sinsentido hablar de intencionalidad mental en aquellos animales que sean capaces de representar el mundo (incluyendo la capacidad de representar a un otro y a sí mismos). Ahora bien, esto último pensamos es posible en la medida en que se satisfagan dos circunstancias: a) que las ciencias del comportamiento como la etología y la psicología reconozcan qué animales presentan procesos cognitivos, tales como el aprendizaje, memoria, solución de problemas, intención, toma de decisiones, etc.; quizá sea innecesario hablar de grados, pues unos tendrán más desarrollada cierta capacidad que otra, por lo que lo importante es b) aceptar que los animales reconocen sus experiencias mentales, las cuales son experiencias "simples" relacionadas a su sobrevivencia. Debemos entender por simpleza que son pensamientos "de asuntos de importancia crucial para ellos; por ejemplo, alimento, predadores y compañeros sociales" (Griffin, 1994:104). Por otro lado, si nos vemos en la necesidad de aceptar la clase de pensamiento de segundo orden, aquel reconocimiento consciente de que están pensando, también creemos se da en ellos, sobre todo en aquellos animales que piensen en sí mismos, justo en relación a estas experiencias simples, fenómeno que se demuestra en su actuar.

- Nociones como voluntad, propósito, capacidad de elección, sentimientos expresivos, pueden ser atribuidos en ciertos animales, en aquellos que cumplan con el requisito de evidenciar estos rasgos mentales en su comportamiento. De hecho, si nos detenemos a pensar, tanto los animales como los humanos manifestamos muchas afinidades: Ambos, - como 
afirma Lindsay-, exhibimos grandes variaciones de temperamento y disposición, exhibimos aficiones, repulsiones y sentimientos, como la ira, cariño, tristeza, impaciencia, placer y dolor; ingenio ante dificultades, ambos adquirimos conocimiento sobre la base de la experiencia perceptual; ambos retenemos e intercambiamos planes e informes, ambos formamos alianzas, ambos evidenciamos sociedades, y los fenómenos de emigración, obediencia, y desviación de la rutina (Lindsay, 1880: 61).

Ahora bien, nuestra postura no es pedante en el sentido de dar la última palabra, por ambos dominios, el filosófico y el biológico queda mucho por decir, y ambas disciplinas hacen una labor loable en analizar conscientemente el mayor número de posibilidades, por un lado teórico epistemológicas, por el lado filosófico, mientras que por el lado biológico son teóricas y empíricas. En este sentido, pensamos que entre los asuntos que tiene que resolver las ciencias del comportamiento para comprometerse en afirmar la intencionalidad animal son por lo menos tres:

i. Establecer si es posible describir los procesos mentales en los animales no humanos, en un lenguaje antropomorfizado; es decir, un lenguaje que tenga como base los actos intencionales humanos.

ii. Desde un punto de vista evolutivo ${ }^{16}$, ¿Qué tipo de rastros o raíces de los procesos mentales humanos se encuentran en mamíferos no humanos con diversos niveles de organización mental?

iii. ¿Cómo se relaciona el término intencional con el término consciente en la vida animal?

Estas preguntas surgen a la luz de que el estudio sobre el tratamiento comparado de las conductas animal y humana se ha considerado desde una visión escéptica por la mayoría de los intelectuales, ya sea por prejuicios o ignorancia; lo cual condujo a evitar cualquier interés por dicho tema (Friedrich, 1968: V). De modo

\footnotetext{
${ }^{16}$ Concedemos la hipótesis de la evolución de la vida en general, sobremanera, por tanto, en la vida animal no humana.
} 
que las vías para tratar el estudio comparativo se ha establecido en dos sentidos: o el Homo sapiens se distingue del nivel animal o bien se considera que hay un continuo entre lo animal y lo humano. En el plano filosófico $-\mathrm{y}$ muy probablemente en otras disciplinas del plano teórico- se ha pensado que el continuo evolutivo es una reducción que debe ser evitada; el eje central de esta afirmación parte de sostener que ni las emociones, ni el discernimiento provienen de "un mero ejercicio de las leyes de la naturaleza" (ídem). En otras palabras el reino de los seres humanos debe distinguirse del otro reino donde impera la ley salvaje. Estipulaciones que las ciencias del comportamiento y diferentes perspectivas filosóficas tratan de descartar en nuestro tiempo. 


\section{BIBLIOGRAFÍA:}

Allen, C. \& Bekoff, M. (1997) Species of Mind. The Philosophy and Biology of Cognitive Ethology, Cambridge: MIT Press.

Aquino, Tomás (1272) Suma de Teología, 4a. ed., Madrid: Biblioteca de autores cristianos, 1988.

Aristóteles Acerca del alma, Trad. Tomás Calvo, Madrid: Gredos, 1988.

Armstrong, D.M. (1961) Perception and the Physical World, London: Routledge and Kegan Paul.

Ayer, A.J. (1971) Lenguaje, verdad y lógica, Buenos Aires: Eudeba.

Bekoff, M. C. (1995) Readings in Animal Cognition, Cambridge, MA: MIT Press.

Brentano, F. (1874) Psychology from an Empirical Standpoint, editado por Linda L. McAlister, London: Routledge, 1995.

Bermudez. J.L. (2003) Thinking without Words. N. Y.: Oxford University Press.

Burkhardt, Jr. (2010) Konrad Lorenz, Elsevier: University of Illinois.

Crystal, J.D. (2010) "Long-interval timing is based on a self-sustaining endogenous oscillator", en Behavioral Processes, 72.

Chisholm, R. M. (1956) "Sentences about believing", en Proceeding of the Aristotelian Society, LVI, 1955-1956, PP.125-147.

University Press.

Darwin, C. (1859) On the Origin of the Species, N. Y.: D. Appleton \& Co. (1873) Expression of the emotions in man and animals. N. Y.: D. Appleton \& Co.

(1871) The descendent of man, N. Y.: D. Appleton \& Co.

Davidson, D. Radical Interpretation en Inquires into Truth and Interpretation (2001a). Oxford: Clarendon Press.

------- Thought and Talk. En Inquires into Truth and Interpretation (2001b). Oxford: Clarendon Press.

Dennett, D. C. (1992) Consciousness Explained, N. Y.: Back Bays Books. 
(1987) The intentional Stance, Massachussetts: The MIT Press

Cambridge.

Descartes, R. (1637) Discurso del Método, estudio preliminar, traducción y notas de Bello Reguera E., Tecnos: Madrid, 2003.

(1641) Meditaciones Metafísicas, Escuela de filosofía Universidad

Arcis, versión electrónica, extraído de:

www.rosariosantodomingo.edu.co/contenido/tarea_2622.pdf

Fodor, J. A. (1975) The Language of Thought, N.Y.: Harper \& Row.

Griffin, D. (1994) Animals Mind, Chicago: University of Chicago Press.

Hauser, M. D. "Minding the behavior of deception", en Machiavellian Intelligence II.

Extensions and Evaluations, editado por Andrrew Whiten y Rihard W. Byrne, 1997, N.Y.: Cambridge University Press.

Hendrichs, $\mathrm{H}$. Diferent roots of Human Intentionality in Mammalian Mentality, en

Erkenntnis (1975-), publicado por Springer, Vol. 51, No. 1, Animal Mind (1999), pp. 145-164.

Heinz, F. (1968) Hombre y animal. Estudios sobre comportamiento, Madrid: Consejo Nacional de Ciencia y Tecnología, 1975.

Husserl, E. (1900-1901) Investigaciones lógicas, Madrid: Alianza, 1999.

(1913) Ideas relativas a una fenomenología pura y una filosofía fenomenológica l, México: F.C.E.

Klopfer, P. H. (1976) Introducción al comportamiento animal: Un siglo de etología. Vol. 256, México: F. C.E.

Kriegel, U. "Consiousness: Phenomenal Consciousness, Access Consciousness, and Scientific Practice", en Thargard P. (ed) Handbook of philosophy of Psychology and Cognitive Science (2006), Amsterdam: North Holland.

López-Farjeat, L. X. (Comp.) (2009) La mente animal. De Aristóteles al aristotelismo árabe y latino a la filosofía contemporánea, México: Los libros de Homero.

Lorenz, K. \& Leyhausen, P (1985). Biología del comportamiento: raíces instintivas de la agresión, el miedo y la libertad, Siglo XXI Editores. 
Lorenz, K. (1961) La evolución de la conducta. Harvard University Press. (1986) Fundamentos de la Etología, Barcelona: Paidós.

Magno, A. M. Sobre el alma. No. 132, Pamplona: Eunsa-Ediciones Universidad de Navarra, 2012.

Manrique, A. Memoria de elefante, [en línea]: documento electrónico en internet, 7/12/2007, Agencia Cyta Instituto Leloir, disponible en el siguiente enlace: http://argos.portalveterinaria.com/noticia/5757/Articulosarchivo/Memoria-deelefante.html.http://argos.portalveterinaria.com/noticia/5757/Articulosarchivo/Memoria-de-elefante.html.

Martínez Contretas, J. (1980) Sartre. La filosofía del hombre. 2a ed., México: Siglo veintiuno editores.

Montaigne, M. (1580) Ensayos, Libro I, Madrid: Casa Editorial Garnier Hermanos. Nagel, T. (1974) "What is it like to be a bat?", en The Philosophical Review, LXXXIII.

Piaget, J. (1977) Los procesos de adaptación, en Buenos Aires: Ediciones Nueva Visión.

Premack, D., Woodruff, G (1978) "Does the Chimpanzee have a Theory of Mind?" en The Behavioral and Brain Sciences, 4, 515-526.

Ryle, G. (1949) The Concept of the Mind, Chicago: University of Chicago Press.

Reznikova, Z. (2007) Animal Intelligence: From Individual to Social Cognition. Cambridge: Cambridge University Press.

Russell, B. (1919) "Descripciones", en La búsqueda del significado, de Valdés, L.M. (comp.), 2000, Madrid: Tecnos.

Romanes, G.J. (1884) Mental evolution in animals, London: Keegan, Paul Trench $\&$ Co.

Sartre, J. P. (1943) El ser y la nada, Buenos Aires: Losada, 2004.

Savage-Rumbaugh, S \& Lewin, R. (1994) "Kanzi: The Ape at the Brink of the Human Mind", en Scientific American, 272.

Searle, J. (1983) Intentionality. Cambridge: Cambridge University Press. (2004) Mind, a Brief introduction, N.Y.: Oxford University Press. 
Skinner, B. F. (1974) Sobre el conductismo, N.Y.: Psicolibro.

Smith, W. J. (1982) La etología de la comunicación, México: F.C.E.

Spencer, H. (1896) Principles of Psychology, 2a. ed. N.Y.: D. Appleton \& Co.

Stanley, J, Williamson T. (2001) "Knowledge How", en The Journal of Philosophy, Vol. 98, No. 8.

Tinbergen, N. "On aims and methods of Ethology", en Zeitschrift für Tierpsychologie, 20: 410-433. 
EL CONCEPTO DE

INTENCIONALIDAD ANIMAL EN

FILOSOFIA, ETOLOGIA Y

PSICOLOGIA COMPARADA.
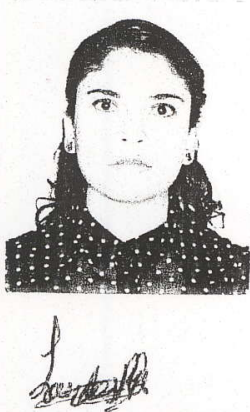

MARIA DE LOURDEŚ RAMIREZ ARGONZA

ALUMNA

REVISÓ

LIC. JULIO CESAR DE LARA ISASSI

DIRECTOR DE SISTEMAS ESCOLARES
En México, D.F., se presentaron a las 14:00 horas del día 10 del mes de julio del año 2014 en la Unidad Iztapalapa de la Universidad Autónoma Metropolitana, los suscritos miembros del jurado:
DR JORGE MARTINEZ CONTRERAS
DRA. VIOLETA BEATRIZ ARECHIGA CORDOVA
DR. JORGE ROBERTO ORNELAS BERNAL
DRA. AURA LETICIA PONCE DE LEON CONTRERAS

Bajola presidencia del primero y con carácter de Secretaria la última, se reunieron para proceder al Examen de Grado cuya denominación aparece al margen, para la obtención del grado de:

MAESTRA EN HUMANIDADES (FILOSOFIA)

DE: MARIA DE LOURDES RAMIREZ ARGONZA

$y$ de acuerdo con el artículo 78 fracción II del Reglamento de Estudios superiores de la universidad Autónoma Metropolitana, los miembros del jurado resolvieron:

$$
\text { Aprobar }
$$

Acto continuo, el presidente del jurado comunicó a la interesada el resultado de la evaluación $y$, en caso aprobatorio, le fue tomada la protesta.

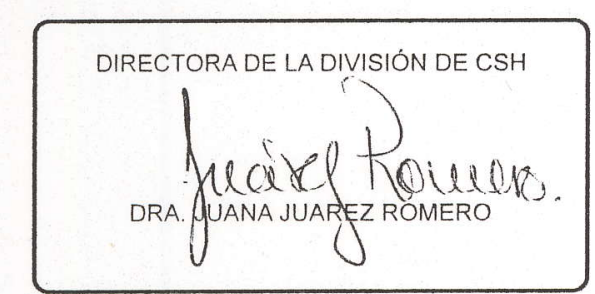

VOCAL

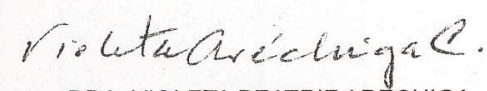

DRA. VIOLETA BEATRIZ ARECHIGA CORDOVA

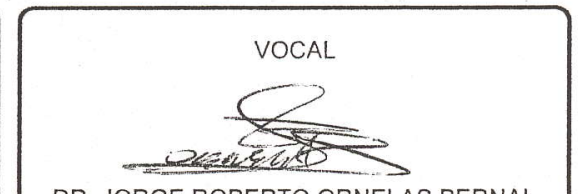

DR. JORGE ROBERTO ORNELAS BERNAL

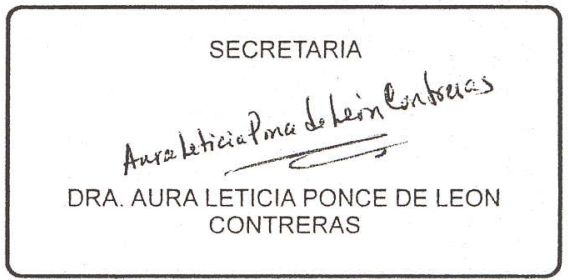

